\title{
Computational modeling of sodium-iodine secondary batteries
}

\author{
Huayang Zhu ${ }^{\mathrm{a}}$, Robert J. Kee $\mathrm{K}^{\mathrm{a}, *}$ \\ ${ }^{a}$ Department of Mechanical Engineering, Colorado School of Mines, Golden, CO 80401, \\ USA
}

\section{Abstract}

This paper develops a computational model and applies it to investigate the performance of a rechargeable battery that is comprised of a moltensodium anode, a NASICON sodium-ion-conducting separator membrane, and a iodine-based cathode. The cathode compartment is comprised of a porouscarbon felt and an aqueous catholyte that supports an iodine redox process. The battery chemistry can be represented globally as $2 \mathrm{Na}^{+}+2 \mathrm{I}^{-} \rightleftharpoons 2 \mathrm{Na}+\mathrm{I}_{2}$. The ion transport is represented in terms of a Nernst-Planck formulation that includes four mobile species within the catholyte, $\mathrm{Na}^{+}, \mathrm{I}^{-}, \mathrm{I}_{3}^{-}$, and $\mathrm{I}_{2}$. The charge transfer chemistry is modeled using a Butler-Volmer formulation. The model considers solubility limits and the potential precipitation of $\mathrm{NaI}$ and $\mathrm{I}_{2}$. Parameter studies investigate the influences of charge and discharge rates, total elemental iodine loading, and effective conductivity of the carbon-felt cathode.

Keywords:

Secondary battery, Molten-sodium, Iodine redox, Computational Modeling,

\footnotetext{
*Corresponding author. Tel: (303) 273-3379.

Email address: rjkee@mines.edu (Robert J. Kee)
} 


\section{Introduction}

Molten sodium can serve as the anode for high-performance rechargeable battery technology. Of course, sodium is an inexpensive, earth-prevalent, non-toxic, environmentally friendly, material. The challenge is to develop compatible sodium-ion conducting separator membranes together with cathode materials and architectures. The present paper focuses on NASICON (Sodium super ionic conductor) as the electrolyte separator membrane and a cathode based on the $\mathrm{I}_{3}^{-} / \mathrm{I}^{-}$redox couple. Although performance depends on more detailed chemistry within the cathode, the overall reaction for the $\mathrm{Na}-\mathrm{I}_{2}$ battery can be written globally as

$$
\begin{gathered}
2 \mathrm{Na}^{+}+2 \mathrm{I}^{-} \underset{\text { discharge }}{\stackrel{\text { charge }}{\rightleftharpoons}} 2 \mathrm{Na}+\mathrm{I}_{2}, \\
\left(E^{\circ}=3.2495 \mathrm{~V}\right) .
\end{gathered}
$$

The objective this paper is to develop and apply a computational model that predicts battery performance. The model represents the coupled chemistry and transport within the anode, separator, and cathode. The underpinning theory and model development concentrates on the cathode, where the chemistry and transport is the most complex. The cathode structure is also the area where the performance depends on numerous design and operational tradeoffs.

Inasmuch as the sodium melting point is $98^{\circ} \mathrm{C}$, molten-sodium batteries must operate at elevated temperature. Depending on the separator and cathode technologies, the sodium melting point may not be the limiting factor in 
setting the operating temperature. For example, higher temperatures may be needed to achieve suitable ion conductivity in the separator membrane. In any case, the requirement for elevated-temperature operation restricts opportunities for practical application. Although Na-based technology may not be suitable for consumer automotive applications, it does offer opportunities for applications such as large-scale grid storage.

[Figure 1 about here.]

Figure 1 illustrates features of a $\mathrm{Na}-\mathrm{I}_{2}$ battery architecture, with the reaction arrows indicating discharge conditions. During discharge the sodium reacts electrochemically at the Na-NASICON separator interface, delivering $\mathrm{Na}^{+}$ions into the separator and electrons through the molten sodium into the external circuit. The charge-transfer reaction may be stated as

$$
\mathrm{Na}^{+}+\mathrm{e}^{-} \underset{\text { discharge }}{\stackrel{\text { charge }}{\rightleftharpoons}} \mathrm{Na}, \quad\left(E^{\circ}=-2.714 \mathrm{~V} \text { vs. NHE }\right) \text {. }
$$

As the battery discharges, the sodium level within the anode compartment decreases.

The $\mathrm{Na}^{+}$produced at the Na-NASICON interface migrates through the NASICON membrane toward the cathode-NASICON interface. The dense NASICON membrane is a pure sodium-ion conductor, with negligible electronic conductivity. Thus, in addition to $\mathrm{Na}^{+}$conductivity, the NASICON serves as the electronic separator between the anode and cathode compartments.

The cathode compartment is filled with a porous carbon felt that is infiltrated with an aqueous catholyte. The catholyte serves as a solvent for 
$\mathrm{Na}^{+}, \mathrm{I}^{-}, \mathrm{I}_{3}^{-}$and $\mathrm{I}_{2}$. During discharge, electrons returning from the external circuit conduct from the cathode current-collector into the carbon felt. At the interfaces between the carbon felt and the catholyte the iodine is reduced to form iodide via a charge-transfer reaction as

$$
2 \mathrm{I}^{-} \underset{\text { discharge }}{\stackrel{\text { charge }}{\rightleftharpoons}} \mathrm{I}_{2}+2 \mathrm{e}^{-}, \quad\left(E^{\circ}=0.5355 \mathrm{~V} \text { vs. NHE }\right) \text {. }
$$

Within the catholyte solution, the iodine can be combined with two iodide ions to form tri-iodide ions (i.e., $\mathrm{I}_{2}+\mathrm{I}^{-} \rightleftharpoons \mathrm{I}_{3}^{-}$). To maintain charge neutrality within the catholyte, $\mathrm{Na}^{+}$must emerge from the separator and enter the catholyte solution. All the mobile ions must be spatially distributed within the catholyte so as to maintain local charge neutrality. Moreover, it is important that the elemental iodine concentration is such that $\mathrm{NaI}$ and $\mathrm{I}_{2}$ remain in solution.

The $\mathrm{I}_{3}^{-} / \mathrm{I}^{-}$redox couple has the potential to be an excellent aqueous-based cathode for sodium-based batteries. The iodine has relatively low molecular weight, high solubility, highly reversible redox reaction rate, and a suitable redox potential. Iodine's aqueous phase solubility is reasonably high because iodine can react with other iodides to form poly-iodides, with the tri-iodide ion being the dominate ionic species in the aqueous solution. Thus, relatively high $\mathrm{I}^{-}$and $\mathrm{I}_{2}$ concentrations can be used, leading to aqueous catholyte with high capacity and high energy density. With respect to the standard hydrogen electrode, the redox potential of the $\mathrm{I}_{3}^{-} / \mathrm{I}^{-}$couple is approximately $0.536 \mathrm{~V}$ and the redox potential of the $\mathrm{I}_{2} / \mathrm{I}^{-}$couple is approximately $0.5335 \mathrm{~V}$. These relatively low redox electric potentials are important to avoid undesired electrolysis of the aqueous solution, such as the oxygen evolution reaction 
(OER), which occurs at the standard redox potential greater than $0.7 \mathrm{~V}$ in the aqueous NaI solution. The tri-iodide/iodide $\left(\mathrm{I}_{3}^{-} / \mathrm{I}^{-}\right)$redox couple in the aqueous catholytes has been studied for a variety of lithium-iodine batteries [1-4], including flow batteries [5, 6].

\section{Mathematical model}

The model is based on fundamental electrochemistry concepts. Chargetransfer reactions are represented in the Butler-Volmer form. Mixed-conducting transport is based on a Nernst-Planck model. In other words, the ion flux is governed by a Nernst-Planck relationship and electrostatic potentials obey the Gauss law. The cathode structure is composed of a porous electronconducting material (e.g., carbon felt), with the pore volume filled with an aqueous catholyte solution. The solid volume of the porous cathode is assumed to be a high-conductivity electron conductor. The mobile species within the catholyte are $\mathrm{Na}^{+}, \mathrm{I}^{-}, \mathrm{I}_{3}^{-}$, and charge-neutral $\mathrm{I}_{2}$. In addition to charge-transfer chemistry at the electrode-electrolyte interfaces, homogeneous reaction is considered within the catholyte. The electrolyte separator membrane is assumed to be a pure $\mathrm{Na}^{+}$conductor (e.g., NASICON). The molten $\mathrm{Na}$ anode is assumed to be a high-conductivity electron conductor. Current collectors at the ends of the electrode compartments are connected to an external circuit that can control the charge and discharge current. The model considers the solubility of $\mathrm{NaI}$ and $\mathrm{I}_{2}$, and hence the possible deleterious precipitation of condensed compounds. Material properties are derived from prior literature wherever possible.

[Figure 2 about here.] 
Figure 2 illustrates the governing equations, the computational domains on which they are applied, and the boundary conditions. The model must represent the electrostatic potentials in the electrode and electrolyte phases. It must also represent the species concentrations in the electrolyte phases. The electrostatic potential and the species concentrations are closely coupled through the system of conservation equations.

The transient model is implemented in a one-dimensional spatial setting, spanning from the anode current collector to the cathode current collector. The spatial operators are discretized using a conservative finite-volume approach. The system is solved computationally using the method of lines.

\subsection{Catholyte concentrations}

Considering the cathode's porous microstructure, the species $\left(\mathrm{Na}^{+}, \mathrm{I}^{-}\right.$, $\mathrm{I}_{3}^{-}, \mathrm{I}_{2}$ ) transport within the catholyte solution can be represented as

$$
\frac{\partial \phi\left[X_{k}\right]}{\partial t}+\nabla \cdot \mathbf{J}_{k}=\phi \dot{\omega}_{k}+A_{\mathrm{s}} \dot{s}_{k},
$$

where $\phi$ is the porosity (catholyte volume fraction) and $\left[X_{k}\right]$ are the species molar concentrations. The transport fluxes are represented in a NernstPlanck formulation as

$$
\mathbf{J}_{k}=-D_{k}^{\mathrm{e}} \nabla\left[X_{k}\right]-\frac{z_{k} F}{R T} D_{k}^{\mathrm{e}}\left[X_{k}\right] \nabla \Phi_{\mathrm{el}},
$$

where $\Phi_{\mathrm{el}}$ is the electrostatic potential in the catholyte solution phase, $T$ is the temperature, $R$ is the gas constant, and $F$ is the Faraday constant. The mobile ions have charge $z_{k}\left(z_{\mathrm{Na}^{+}}=1, z_{\mathrm{I}^{-}}=-1, z_{\mathrm{I}_{3}^{-}}=-1, z_{\mathrm{I}_{2}}=0\right)$. The effective porous-media diffusion coefficients are represented as $D_{k}^{\mathrm{e}}$, which are 
related to the bulk diffusion coefficients $D_{k}$ (Sect. 3.1) as

$$
D_{k}^{\mathrm{e}}=D_{k} \phi^{\gamma}
$$

where $\gamma$ is the Bruggemann exponent, which is typically $\gamma \approx 3 / 2$.

Species molar production rates due to homogeneous chemical reactions within the catholyte are represented as $\dot{\omega}_{k}$. The homogeneous chemistry can be represented globally in terms of iodine-iodide redistribution as $\mathrm{I}_{2}+\mathrm{I}^{-} \rightleftharpoons \mathrm{I}_{3}^{-}$. The species molar production rates resulting from electrochemical reaction at the distributed electrode surfaces are represented as $\dot{s}_{k}$ and $A_{\mathrm{s}}$ is the specific interface area (i.e., surface area per unit volume). The charge-transfer chemistry at cathode-catholyte interfaces can be represented globally as Eq. 3. Details of the chemistry are discussed subsequently (Sect. 4).

The catholyte domain spans the space between the NASICON and the cathode current collector (cf., Fig. 2). At the NASICON interface, all species fluxes vanish, except the $\mathrm{Na}^{+}$flux. At the cathode current-collector interface all species fluxes vanish. In other words, with the exception of $\mathrm{Na}^{+}$, all the catholyte-species boundary conditions may be represented as $\mathbf{n} \cdot \mathbf{J}_{k}=0$, where $\mathbf{n}$ is the outward-pointing unit vector. At the NASICON interface, the boundary condition is

$$
\mathbf{n} \cdot \mathbf{J}_{\mathrm{Na}^{+}}=\frac{i_{\mathrm{ex}}}{F}
$$

where $i_{\mathrm{ex}}$ is the specified current that is delivered to, or supplied by, the external circuit.

\subsection{Cathode charge conservation}

The cathode structure is comprised of a porous carbon felt (electrode) that is infiltrated with the catholyte solution (electrolyte). As illustrated 
in Fig. 2, the cathode phase spans the domain between the NASICON and the cathode current collector. The carbon felt is a pure electronic conductor whose local electrostatic potential $\Phi_{\mathrm{ed}}$ is governed by

$$
\frac{\partial \rho_{\mathrm{ed}}}{\partial t}+\nabla \cdot \mathbf{i}_{\mathrm{ed}}=-A_{\mathrm{s}} \dot{s}_{\mathrm{e}}
$$

where $\rho_{\text {ed }}$ is the local charge density due to the double-layer capacitance between the electrode and electrolyte interfaces, and the current density is represented as

$$
\mathbf{i}_{\mathrm{ed}}=-\sigma_{\mathrm{ed}} \nabla \Phi_{\mathrm{ed}}
$$

The specific interface area between the electrode and electrolyte is $A_{\mathrm{s}}$ and $\dot{s}_{\mathrm{e}}$ is the net charge-transfer rate associated with the charge-transfer chemistry (Eq. 3) at the interface,

$$
\dot{s}_{\mathrm{e}}=\sum_{k} z_{k} F \dot{s}_{k}
$$

The effective electrical conductivity depends on the porosity,

$$
\sigma_{\text {ed }}=\sigma_{\text {ed }}^{\circ}(1-\phi)^{\gamma}
$$

where $(1-\phi)$ is the solid-phase volume fraction, $\sigma_{\text {ed }}^{\circ}$ is the electric conductivity of dense solid phase, and $\gamma$ is a Bruggemann exponent.

Two boundary conditions are needed to solve Eq. 8. At the cathode current collector the electrostatic potential is fixed at some reference potential (typically zero) as

$$
\Phi_{\text {ed }}=\Phi_{\text {ref }}
$$

At the interface with NASICON, there can be no electric current between the carbon felt (electrode) and the NASICON. Thus,

$$
\mathbf{n} \cdot \mathbf{i}_{\mathrm{ed}}=0
$$




\subsection{Electrolyte charge conservation}

The catholyte and the NASICON are both electrolytes and the model must represent the electrostatic potential distributions within these materials. Although the catholyte and the NASICON are clearly very different, the same basic charge-conservation equation applies. As illustrated in Fig. 2, it is convenient in the present model to represent the electrolyte charge conservation on a domain that spans NASICON and the catholyte. Of course, the chemistry and the material properties are greatly different between the NASICON and the catholyte.

The general charge-conservation equation may be represented as

$$
\frac{\partial \rho_{\mathrm{el}}}{\partial t}+\nabla \cdot \mathbf{i}_{\mathrm{el}}=A_{\mathrm{s}} \dot{s}_{\mathrm{e}}
$$

where $\rho_{\mathrm{el}}$ is the local charge density. The electrolyte current density may be represented in terms of an Ohm's law contribution and a concentration contribution as

$$
\mathbf{i}_{\mathrm{el}}=\sum_{k} z_{k} F \mathbf{J}_{k}=\mathbf{i}_{\mathrm{el}, \mathrm{Ohm}}+\mathbf{i}_{\mathrm{el}, \mathrm{conc}} .
$$

The Ohm's law contribution is written as

$$
\mathbf{i}_{\mathrm{el}, \mathrm{Ohm}}=-\sigma_{\mathrm{el}} \nabla \Phi_{\mathrm{el}}
$$

where the conductivity is $\sigma_{\mathrm{el}}$. Within the catholyte solution, the conductivity is evaluated from the Nernst-Einstein relationship as

$$
\sigma_{\mathrm{el}}=\sum_{k} \frac{z_{k}^{2} F^{2}}{R T} D_{k}^{\mathrm{e}}\left[X_{k}\right],
$$

where $D_{k}^{\mathrm{e}}$ are effective diffusion coefficients for the mobile charged species (Eq. 6) and $\left[X_{k}\right]$ are molar concentrations. In the solid NASICON, the conductivity is simply the $\mathrm{Na}^{+}$conductivity, $\sigma_{\mathrm{el}}=\sigma_{\mathrm{Na}^{+}}$. 
Within the catholyte the concentration contribution to the current density is

$$
\mathbf{i}_{\mathrm{el}, \mathrm{conc}}=-\sum_{k} z_{k} F D_{k}^{\mathrm{e}} \nabla\left[X_{k}\right] .
$$

Within the NASICON, the current density is assumed to be purely Ohmic, meaning that there is no concentration-gradient contribution.

Within the catholyte, there is charge transfer between the electrode and electrolyte phases. The term $\dot{s}_{\mathrm{e}}$ in Eq. 14 is the same as in Eq. 8, but has the opposite sign. Because there is no charge transfer within the NASICON, $\dot{s}_{\mathrm{e}}=0$.

The local charge density within the electrolyte phases can be represented as $\rho_{\mathrm{el}}=\sum z_{k} F\left[X_{k}\right]$. Except for very fast transients, such as double-layer charging near electrode interfaces, charge-neutrality within the electrolyte solutions requires that $\partial \rho_{\mathrm{el}} / \partial t=0$. The present model neglects these fast transients, thus considering the steady-state version of Eq. 14.

Solving Eq. 14 requires a boundary condition at the interface between the catholyte and the cathode current collector and a boundary condition at the interface between the NASICON and the molten sodium (cf., Fig. 2). At the cathode current collector, the electrical current density must vanish, $\mathbf{n} \cdot \mathbf{i}_{\mathrm{el}}=0$. At the molten-sodium interface, the net current current density must be equal to the current imposed by the external circuit. That is,

$$
\mathbf{n} \cdot \mathbf{i}_{\mathrm{el}}=i_{\mathrm{ex}} \cdot
$$

In principle, Eq. 14 could be solved on the catholyte domain and on the NASICON domain. In that case, interface conditions would be needed at the NASICON-catholyte interface. In other words, the electrostatic potential 
and the charge flux must be continuous across the interface. The present formulation solves a single discretized equation, but simply changes terms to represent the materials in the equations on both sides of the interface.

\section{Physical and chemical properties}

[Table 1 about here.]

\subsection{Diffusion coefficients}

Mobile-species diffusion coefficients $D_{k}\left(\mathrm{~m}^{2} \mathrm{~s}^{-1}\right)$ within the catholyte play central roles in the battery performance. Temperature-dependent diffusion coefficients in the dilute aqueous solutions can be formally expressed as $[7,8]$,

$$
D_{k}(T) \mu(T)=A_{k} T^{B_{k}} \exp \left(-\frac{E_{k}}{R T}\right)
$$

where $\mu$ is the viscosity ( $\mathrm{Pa} \mathrm{s}$ ) of the pure water [9], and the parameters $A_{k}, B_{k}$, and $E_{k}$ are species-specific parameters. Table 1 lists the diffusivity parameters used in the present study. The parameters for $\mathrm{Na}^{+}$are taken from Anderko and Lencka [7], considering the relationship of the ionic-species diffusion coefficients with the limiting conductivities $\Lambda_{k}^{\circ}$,

$$
\Lambda_{k}^{\circ}=\frac{z_{k}^{2} F^{2}}{R T} D_{k} .
$$

The parameters for $I_{2}$ and $I_{3}^{-}$are obtained by refitting elevated-temperature measurements reported by Cantrel, et al. [10]. Parameters for $\mathrm{I}^{-}$are based on refitting the experimental data by Cantrel, et al. [11]. Table 1 also shows the diffusion coefficients evaluated at $25^{\circ} \mathrm{C}$ and $120^{\circ} \mathrm{C}$. 


\subsection{NASICON conductivity}

The present model assumes a NASICON membrane as developed by Ceramatec, Inc. (Salt Lake City, UT). The conductivity for this material $\sigma$ ( $\mathrm{S}$ $\mathrm{cm}^{-1}$ ) can be represented empirically as $[12,13]$

$$
\ln (\sigma T)=11.60996-\frac{3418.133}{T}
$$

where temperature $T$ (in Kelvins) is below $400{ }^{\circ} \mathrm{C}$. At $T=25{ }^{\circ} \mathrm{C}, \sigma=$ $3.879 \times 10^{-3} \mathrm{~S} \mathrm{~cm}^{-1}$; at $T=120{ }^{\circ} \mathrm{C}, \sigma=4.696 \times 10^{-2} \mathrm{~S} \mathrm{~cm}^{-1}$.

\subsection{Carbon felt cathode}

Carbon felt electrodes can be made by matting, condensing and pressing carbon fibers. Such materials can have high chemical stability, large specific surface area, good flow permeability, and high electric conductivity [14]. The typical porosity $\phi$ of carbon felt electrodes is around $\phi \approx 0.8$ and the fiber diameter is typically $d_{\mathrm{f}} \approx 10 \mu \mathrm{m}$. The specific area $A_{\mathrm{s}}$ can be expressed as $[15]$

$$
A_{\mathrm{s}}=\frac{4(1-\phi)}{d_{\mathrm{f}}} .
$$

The electric conductivity of the solid matrix $\sigma_{\mathrm{ed}}\left(\mathrm{S} \mathrm{m}^{-1}\right)$ is related to the porosity $\phi$ of the carbon-felt porous electrodes as [16]

$$
\sigma_{\text {ed }}=10+2800\left(1-\frac{\phi}{\phi^{\circ}}\right)^{1.55},
$$

for $0.68<\phi / \phi^{\circ}<1$ where $\phi^{\circ}$ is the porosity prior to any mechanical compression. In this study, Eq. 24 is used to estimate the effective electric conductivity of the carbon-felt porous electrode instead of the generic expression of Eq. 11 for the porous electrode. 


\section{Chemical and electrochemical reactions}

The Butler-Volmer formulation is used to represent the global chargetransfer rate at electrode-electrolyte interfaces as

$$
i_{\mathrm{e}, \mathrm{BV}}=i_{0}\left[\exp \left(\frac{\alpha_{\mathrm{a}} F \eta_{\mathrm{act}}}{R T}\right)-\exp \left(-\frac{\alpha_{\mathrm{c}} F \eta_{\mathrm{act}}}{R T}\right)\right]
$$

where the activation overpotential

$$
\eta_{\text {act }}=\left(\Phi_{\mathrm{ed}}-\Phi_{\mathrm{el}}\right)-E^{\mathrm{eq}}
$$

and the equilibrium electric potential difference $E^{\mathrm{eq}}$ is the electric potential difference at which the forward and backward charge-transfer rates are equal to the exchange current density $i_{0} . \quad \alpha_{\mathrm{a}}$ and $\alpha_{\mathrm{c}}$ are the anodic and cathodic symmetric factors, respectively.

\section{1. $\mathrm{Na}^{+} / \mathrm{Na}$ charge transfer kinetics}

The reversible half-cell potential of the electrochemical reaction (Eq. 2) at the metallic sodium-NASICON interfaces can be expressed as

$$
E_{\mathrm{Na}^{+}}^{\mathrm{eq}}=E_{\mathrm{Na}^{+}}^{\circ}+\frac{R T}{F} \ln a_{\mathrm{Na}^{+}},
$$

The activity of sodium ion is defined as $a_{\mathrm{Na}^{+}}=\gamma_{\mathrm{Na}^{+}}\left[\mathrm{Na}^{+}\right] /\left[\mathrm{Na}^{+}\right]^{\circ}$ where the activity coefficient $\gamma_{\mathrm{Na}^{+}}$is assumed to be 1 , and the concentration of sodium ion at the standard state $\left[\mathrm{Na}^{+}\right]^{\circ}$ is equal to $1 \mathrm{M}$. The standard reduction potential $E_{\mathrm{Na}^{+}}^{\circ}=-2.714 \mathrm{~V}$ with respect to the standard hydrogen electrode. The exchange current density can be expressed as

$$
i_{0}=i_{0}^{\circ}\left(\frac{\left[\mathrm{Na}^{+}\right]}{\left[\mathrm{Na}^{+}\right]^{*}}\right)^{\alpha_{\mathrm{a}}} .
$$


where $i_{0}^{\circ}$ is an empirical fitting parameter for the exchange current density, and the reference concentrations of $\left[\mathrm{Na}^{+}\right]^{*}$ is taken to be $1 \mathrm{M}$. Because the Butler-Volmer equation represents the net charge-transfer rates rather than the elementary mass-action kinetics $[17,18]$, the exponent for the sodium-ion concentration $\left[\mathrm{Na}^{+}\right]$is usually different from the stoichiometric coefficient of the charge-transfer reaction.

\subsection{Iodine redistribution chemistry}

Although iodine $\left(\mathrm{I}_{2}\right)$ is soluble in a sodium iodide aqueous solution, the equilibrium iodine concentration is relatively small compared to iodide and tri-iodide concentrations. Assuming that iodine precipitation is to be avoided, the redox process largely occurs between the iodine and tri-iodide couple within the catholyte solution. The $\mathrm{I}^{-} / \mathrm{I}_{3}^{-} / \mathrm{I}_{2}$ redox processes have been widely investigated in conventional (i.e., water, acetonitrile, DMSO) and ionic-liquid solvents for dye-sensitized solar cells [19-22].

The redox chemistry for the iodide/iodine $\left(\mathrm{I}^{-} / \mathrm{I}_{2}\right)$ couple on the surface of inert electrodes (e.g., platinum or carbon) can be expressed globally as Reaction 3. However, based on measurements by Wroblowa and Saunders [23], a two-step process provides a better physical representation as

$$
\mathrm{I}_{2}+2(\mathrm{~s}) \rightleftharpoons 2 \mathrm{I}(\mathrm{s}),
$$

$$
\mathrm{I}^{-}+(\mathrm{s}) \rightleftharpoons \mathrm{I}(\mathrm{s})+\mathrm{e}^{-},
$$

where $\mathrm{I}(\mathrm{s})$ is the adsorbed iodine on the electrode surface, and (s) is the unoccupied or empty site on the electrode surface. The present model builds on this two-step cathode chemistry. 
Assuming Reaction 30 to be the rate-limiting step, the equilibrium of Reaction 29 can be represented as

$$
\frac{\theta_{\mathrm{I}}}{\theta_{\mathrm{v}}}=\left(K_{29}\left[\mathrm{I}_{2}\right]\right)^{1 / 2},
$$

where $\theta_{\mathrm{I}}$ and $\theta_{\mathrm{v}}$ are the site fractions of $\mathrm{I}(\mathrm{s})$ and $(\mathrm{s})$ on the electrode surface and $K_{29}$ is the equilibrium constant. Assuming $\theta_{\mathrm{I}}+\theta_{\mathrm{v}}=1, \theta_{\mathrm{I}}$ and $\theta_{\mathrm{v}}$ can be evaluated as

$$
\theta_{\mathrm{v}}=\frac{1}{1+\left(K_{29}\left[\mathrm{I}_{2}\right]\right)^{1 / 2}}
$$

$$
\theta_{\mathrm{I}}=\frac{\left(K_{29}\left[\mathrm{I}_{2}\right]\right)^{1 / 2}}{1+\left(K_{29}\left[\mathrm{I}_{2}\right]\right)^{1 / 2}} \text {. }
$$

The current density resulting from the rate-limiting charge-transfer process (Eq. 30) can be represented in elementary (Marcus) form as

$$
i_{\mathrm{e}}=k_{30, \mathrm{f}} \exp \left(\frac{\beta_{\mathrm{a}} F E}{R T}\right)\left[\mathrm{I}^{-}\right] \Gamma \theta_{\mathrm{v}}-k_{30, \mathrm{~b}} \exp \left(-\frac{\beta_{\mathrm{c}} F E}{R T}\right) \Gamma \theta_{\mathrm{I}},
$$

where $E$ is the electrostatic-potential difference between electrode and electroyte phases and $\Gamma$ is the available site density. The anodic and cathodic symmetric factors are $\beta_{\mathrm{a}}$ and $\beta_{\mathrm{c}}$, with $\beta_{\mathrm{a}}+\beta_{\mathrm{c}}=1$ for an elementary (singleelectron transfer) reaction. $k_{30, \mathrm{f}}$ and $k_{30, \mathrm{~b}}$ are the forward and backward rate coefficients of Reaction 30. Representing the current density in ButlerVolmer form, the exchange current density $i_{0}$ as functions of iodine and iodide concentrations can be expressed as

$$
i_{0}=i_{0}^{\circ} \frac{\left(\left[\mathrm{I}_{2}\right] /\left[\mathrm{I}_{2}\right]^{*}\right)^{\beta_{\mathrm{a}} / 2}\left(\left[\mathrm{I}^{-}\right] /\left[\mathrm{I}^{-}\right]^{*}\right)^{1-\beta_{\mathrm{a}}}}{1+\left(\left[\mathrm{I}_{2}\right] /\left[\mathrm{I}_{2}\right]^{*}\right)^{1 / 2}},
$$

where the reference iodine concentration $\left[\mathrm{I}_{2}\right]^{*}=K_{29}^{-1}$, which is considered to be much larger than $\left[\mathrm{I}_{2}\right]$ such that $\theta_{\mathrm{I}} \ll 1$ and $\theta_{\mathrm{v}} \approx 1$ [23]. The reference iodide concentration $\left[\mathrm{I}^{-}\right]^{*}$ is taken as $1 \mathrm{M}$. The equilibrium reversible potential 
283

$E_{\mathrm{I}^{-} / \mathrm{I}_{2}}^{\mathrm{eq}}$ can be expressed as

$$
E_{\mathrm{I}^{-} / \mathrm{I}_{2}}^{\mathrm{eq}}=E_{\mathrm{I}^{-} / \mathrm{I}_{2}}^{\circ}+\frac{R T}{2 F} \ln \frac{a_{\mathrm{I}_{2}}}{a_{\mathrm{I}^{-}}^{2}},
$$

The activity for $\mathrm{I}_{2}$ is defined as $a_{\mathrm{I}_{2}}=\gamma_{\mathrm{I}_{2}}\left[\mathrm{I}_{2}\right] /\left[\mathrm{I}_{2}\right]^{\circ}$, and the activity for $\mathrm{I}^{-}$ is $a_{\mathrm{I}^{-}}=\gamma_{\mathrm{I}^{-}}\left[\mathrm{I}^{-}\right] /\left[\mathrm{I}^{-}\right]^{\circ}$. The activity coefficients $\gamma_{\mathrm{I}_{2}}$ and $\gamma_{\mathrm{I}^{-}}$are assumed to be 1 , and the concentrations at the standard state $\left[\mathrm{I}_{2}\right]^{\circ}$ and $\left[\mathrm{I}^{-}\right]^{\circ}$ are equal to $1 \mathrm{M}$. The redox potential of iodine/iodide couple at the standard state is $E_{\mathrm{I}^{-} / \mathrm{I}_{2}}^{\circ}=0.5335 \mathrm{~V}$ with respect to the hydrogen standard electrode.

The iodide and iodine can combine homogeneously to form the complex polyhalogen tri-iodide anion,

$$
\mathrm{I}_{2}+\mathrm{I}^{-} \underset{k_{37, \mathrm{~b}}}{\stackrel{k_{37, \mathrm{f}}}{\rightleftharpoons}} \mathrm{I}_{3}^{-},
$$

where the forward rate coefficient $k_{37, \mathrm{f}}$ and backward rate coefficient $k_{37, \mathrm{~b}}$ are related to the equilibrium constant $K_{37}$ in the usual way as $K_{37}=k_{37, \mathrm{f}} / k_{37, \mathrm{~b}}$. Because of the formation of the intermediate tri-iodide, the processes of the iodide oxidation and iodine reduction may proceed phenomenally or apparently in two steps as

$$
3 \mathrm{I}^{-} \rightleftharpoons \mathrm{I}_{3}^{-}+2 \mathrm{e}^{-}, \quad\left(E^{\circ}=0.536 \mathrm{~V} \text { vs. NHE }\right)
$$

$$
2 \mathrm{I}_{3}^{-} \rightleftharpoons 3 \mathrm{I}_{2}+2 \mathrm{e}^{-}, \quad\left(E^{\circ}=0.5355 \mathrm{~V} \text { vs. NHE }\right)
$$

which may lead to two observable voltammetric processes or waves. The potential gap of the two voltammetric waves is proportional to the magnitude of equilibrium constant of the tri-iodide formation reaction $K_{37}$. 


\subsection{Boiling temperature of aqueous NaI solution}

Briggs and Geigle [24] reported the boiling temperatures of the aqueous sodium iodide solution as function of the weight percentage of sodium iodide in water at about 0.98 atmospheric pressure as shown in Fig. 3. As illustrated in Fig. 3, the boiling temperature increases as more sodium iodide is added into the water. The boiling temperature is about $120^{\circ} \mathrm{C}$ at the NaI weight percentage of $64 \%$ with the corresponding molar concentration of $\mathrm{NaI}$ of about $8 \mathrm{M}$. At the saturation point where the $\mathrm{NaI}$ weight percentage is about $76 \%$ and the NaI molar concentration is about $11 \mathrm{M}$, the boiling temperature can reach to about $142{ }^{\circ} \mathrm{C}$. In this study, the operating temperature of the battery is chosen to be $120^{\circ} \mathrm{C}$, which is above the melting temperature of metal sodium within the anode $\left(97.79{ }^{\circ} \mathrm{C}\right)$, and below the boiling temperature of aqueous $\mathrm{NaI}$ solution with appropriate $\mathrm{NaI}$ concentrations.

[Figure 3 about here.]

\subsection{Equilibrium constant of tri-iodide formation}

The reaction equilibrium constant of the tri-iodide formation $K_{37}$ depends highly on the solvents [25]. For the aqueous solutions, the enthalpy and entropy changes at $25^{\circ} \mathrm{C}$ are $\Delta H_{37}^{\circ}=-17.0 \mathrm{~kJ} \mathrm{~mol}^{-1}, \Delta S_{37}^{\circ}=-0.6 \mathrm{~J} \mathrm{~K}^{-1}$ $\mathrm{mol}^{-1}$ respectively, and $K_{37} \approx 700$ at $25{ }^{\circ} \mathrm{C}$ [26]. The equilibrium constant $K_{37}$ at high temperature has been widely investigated [26-28] and can be represented empirically as [26, 29]

$$
\log K_{37}=555.0 / T+7.355-2.575 \log T
$$

where $T$ is in Kelvins and $K_{37}$ has molarity units as $\mathrm{M}^{-1}$. Guo, et al. [30] have compared several alternative temperature-dependent correlations for $K_{37}$. 
The equilibrium molar concentrations of $\mathrm{I}^{-}, \mathrm{I}_{2}$ and $\mathrm{I}_{3}^{-}$within the aqueous catholyte solution at a given iodine element concentration [I], sodium ion concentration $\left[\mathrm{Na}^{+}\right]$, and temperature can be evaluated based on the equilibrium relationship

$$
\frac{\left[\mathrm{I}_{3}^{-}\right]}{\left[\mathrm{I}^{-}\right]\left[\mathrm{I}_{2}\right]}=K_{37}
$$

together with the element balance

$$
\left[\mathrm{I}^{-}\right]+2\left[\mathrm{I}_{2}\right]+3\left[\mathrm{I}_{3}^{-}\right]=[\mathrm{I}]
$$

and charge balance

$$
\left[\mathrm{I}^{-}\right]+\left[\mathrm{I}_{3}^{-}\right]=\left[\mathrm{Na}^{+}\right]
$$

Considering $[\mathrm{I}]=8.0 \mathrm{M}$ and $\left[\mathrm{Na}^{+}\right]=3.81 \mathrm{M}$ at $T=25^{\circ} \mathrm{C}$, the equilibrium concentrations are $1.716 \mathrm{M}$ for $\left[\mathrm{I}^{-}\right], 2.09 \mathrm{M}$ for $\left[\mathrm{I}_{3}^{-}\right]$and $1.74 \times 10^{-3} \mathrm{M}$ for $\left[\mathrm{I}_{2}\right]$, which indicates that the equilibrium iodine molar concentration is much smaller than the equilibrium iodide and tri-iodide molar concentrations.

\section{Solubility and state of charge}

The solubility of sodium iodide in pure water at $25^{\circ} \mathrm{C}$ is $184.2 \mathrm{~g}$ per 100 $\mathrm{g}$ of water, at which point the solution density is $1.9169 \times 10^{3} \mathrm{~kg} \mathrm{~m}^{-3}$ [31] Consequently, the saturated $\mathrm{NaI}$ concentration is $[\mathrm{NaI}]_{\max } \approx 8.286 \mathrm{M}$. Upon the full discharge of $\mathrm{Na}-\mathrm{I}_{2}$ batteries, all the iodine is oxidized to NaI. Because the total iodine element concentration [I] remains constant within the catholyte solution, precipitation of sodium iodine can be avoided as long as $[\mathrm{I}] \leq[\mathrm{NaI}]_{\max }$ under fully discharged conditions. The solubility of sodium iodide in pure water increases as the temperature increases. At $100{ }^{\circ} \mathrm{C}, 302$ $\mathrm{g}$ of sodium iodide can dissolve into $100 \mathrm{~g}$ of water; at $120^{\circ} \mathrm{C} 310 \mathrm{~g}$ of sodium 
iodide can dissolve into $100 \mathrm{~g}$ of water [32]. The saturated molar concentration of sodium iodide is $[\mathrm{NaI}]_{\max } \approx 11.1 \mathrm{M}$ at $100{ }^{\circ} \mathrm{C}$ and $[\mathrm{NaI}]_{\max } \approx 11.2 \mathrm{M}$ at $120{ }^{\circ} \mathrm{C}$.

Iodine $\left(\mathrm{I}_{2}\right)$ is a bluish-black solid below its melting temperature of 113.5 ${ }^{\circ} \mathrm{C}$. It volatilizes into a blue-violet gas with an irritating odor at the room temperature. Iodine is slightly soluble in water and becomes more soluble as the temperature increases. The water solubility of iodine is $0.34 \mathrm{~g}$ per liter at $25^{\circ} \mathrm{C}$, then increases to $0.78 \mathrm{~g}$ per liter at $50{ }^{\circ} \mathrm{C}$. Iodine is more soluble in sodium-iodide solutions because of formation of tri-iodide through combination of iodine with iodide. At $25^{\circ} \mathrm{C}$, the iodine solubility is related to the sodium-iodide molar concentration in water as [33]

$$
\left[\mathrm{I}_{2}\right] \approx 0.55[\mathrm{NaI}]
$$

Therefore, for a specified iodine element concentration $[\mathrm{I}]$, the sodium ion concentration $\left[\mathrm{Na}^{+}\right]$must be greater than about $0.47619[\mathrm{I}]$, such that precipitation of iodine can be avoided during charging the $\mathrm{Na}-\mathrm{I}_{2}$ batteries (i.e., $\left.\left[\mathrm{Na}^{+}\right]_{\min }=0.47619[\mathrm{I}]\right)$.

Table 2 lists fully charged and discharged species molar concentrations within the catholyte at four iodine element concentrations: 4.0, 6.0, 8.0 and 10.0 M. The sodium iodine concentration is set to be below the solubility limit to avoid $\mathrm{NaI}$ precipitation at the fully discharged state, and to be high enough to avoid $\mathrm{I}_{2}$ precipitation at the fully charged state. During the charging and discharging processes, the species molar concentrations vary spatially through the cathode. It is important to monitor the local variation of the species molar concentrations such that $\left[\mathrm{Na}^{+}\right] \leq[\mathrm{NaI}]_{\max }$ and $\left[\mathrm{Na}^{+}\right] /[\mathrm{I}] \geq$ 0.476 to avoid any local precipitation of $\mathrm{NaI}$ and $\mathrm{I}_{2}$ through the cathode. 
The state of charge (SOC) as a relative measure of the amount of energy storage in the Na- $\mathrm{I}_{2}$ battery can be defined based on the species concentrations within the catholyte solution. Because the practical cell capacity seeks to remain within the precipitation limits, the sodium ion concentration during the charge and discharge processes should be maintained in the range of $0.47619[\mathrm{I}] \leq\left[\mathrm{Na}^{+}\right] \leq[\mathrm{I}]$ at a specified iodine element concentration $[\mathrm{I}]$. The state of charge for the Na- $\mathrm{I}_{2}$ battery may be defined as

$$
\mathrm{SOC}=\frac{[\mathrm{I}]-\overline{\left[\mathrm{Na}^{+}\right]}}{[\mathrm{I}]-\left[\mathrm{Na}^{+}\right]_{\min }},
$$

which varies from zero in the fully discharged state to unity in the fully charged state. The average molar concentrations within the catholyte $\overline{\left[X_{k}\right]}$ are defined as

$$
\overline{\left[X_{k}\right]}=\frac{1}{L_{\mathrm{c}}} \int_{0}^{L_{\mathrm{c}}}\left[X_{k}\right] d x,
$$

where $L_{\mathrm{c}}$ is the thickness of the catholyte.

[Table 2 about here.]

\section{Discretization and software implementation}

The solution algorithm generally follows the method-of-lines [34, 35]. The spatial operators in Eqs. 4 and 14 are discretized using a conservative finitevolume formulation. After the spatial operators of the partial differential equations are discretized, the resulting system forms a system of ordinary differential-algebraic equations (DAE). The DAEs are solved using the LIMEX software [36]. The numerical algorithm is implemented in Fortran, using electrochemical extensions of the Chemkin software [35]. Because Chemkin 
package was written initially for gas-phase chemistry, new functionality was added to handle the thermodynamics of liquid electrolyte solutions.

\section{Results and discussion}

A nominal battery architecture and operating conditions are used to illustrate the model and explore salient aspects of model-predicted performance. Table 3 summarizes some of the geometric and chemical parameters. Table 1 lists transport parameters. Both the molten-sodium anode and the porous cathode structure are $10 \mathrm{~mm}$ thick and the NASICON separator is $200 \mu \mathrm{m}$ thick. The cell operating temperature is assumed to be $120^{\circ} \mathrm{C}$. The nominal conductivity of the carbon felt is $\sigma_{\text {ed }}=100 \mathrm{~S} \mathrm{~m}^{-1}$. The nominal charge and discharge rates are assumed to be $1 \mathrm{C}$. The current density at $1 \mathrm{C}$ is about $90 \mathrm{~mA} \mathrm{~cm}^{-2}$.

The model predicts spatial profiles of species concentration and electrostaticpotential. The overall cell performance is characterized in terms of the cell voltage, state of charge, and solubility limits. Following discussion of the nominal performance, physical parameters and operating conditions are varied to study their influences on performance. These studies consider the effects of charge/discharge rates, total elemental iodine concentration, and electrical conductivity of the porous carbon-felt cathode.

[Table 3 about here.]

[Figure 4 about here.]

\subsection{Charge and discharge characterization}

[Figure 5 about here.] 
Under the nominal conditions, Fig. 4 shows the cell voltages as functions of the state of charge (SOC) and time during the first charge and discharge cycles. The initial species concentrations within the catholyte are assumed to be spatially uniform in the fully discharged state (Table $2,[\mathrm{I}]=8 \mathrm{M}$ ) and the charge and discharge rates are set to be $1 \mathrm{C}$. The solid lines of Fig. 4 shows that the cell is charged from the fully discharged state (i.e., $\mathrm{SOC}=0.0$ ). At the charging rate of $1 \mathrm{C}$, the cell voltage $E_{\text {cell }}$ is about $3.05 \mathrm{~V}$ at $\mathrm{SOC}=0.0$, and increases continuously to about $3.19 \mathrm{~V}$ at $\mathrm{SOC} \approx 0.5$, and finally reaches to $3.26 \mathrm{~V}$ at $\mathrm{SOC} \approx 0.94$ because the sodium-ion concentration approaches $\left[\mathrm{Na}^{+}\right] /[\mathrm{I}]=0.476$. Immediately upon achieving the maximum charged state, a $1 \mathrm{C}$ discharge is initiated. Reversing the current density to the discharge mode causes the cell voltage to drop to approximately $3.03 \mathrm{~V}$. The battery continues to discharge at $1 \mathrm{C}$ until a lower-limit SOC is achieved where $\mathrm{NaI}$ would begin to precipitate. At this nearly discharged point, the cell voltage is $E_{\text {cell }}=2.82 \mathrm{~V}$. As represented by the solid lines in Fig. 4, the second $1 \mathrm{C}$ charge cycle begins immediately upon reaching the first discharge limit. The process can continue in a limit cycle for many charge-discharge cycles. If the charge/discharge rates were lower, the battery could achieve its equilibrium fully charged and discharged states. At high rates, the envelope of the limit cycle would shrink.

[Figure 6 about here.]

\subsubsection{Charging, $S O C=0.5$}

Figure 5 shows solution profiles at $\mathrm{SOC}=0.5$ of the first charge cycle ("star" on Fig. 4). By this point in the charge, significant spatial variation 
is evident in all the profiles. During charging, $\mathrm{Na}^{+}$is being transported from the cathode toward the NASICON and the anode. The gradients of both the $\mathrm{Na}^{+}$and the electrolyte electrostatic potential $\Phi_{\mathrm{el}}$ are positive. Thus the concentration and migration contributions in the Nernst-Planck flux (cf., Eq. 5) are in the direction of driving $\mathrm{Na}^{+}$toward the NASICON. During charging, the cathode charge-transfer reaction (Eq. 3) is proceeding in the anodic direction (i.e., producing electrons and iodine). Thus, the $\mathrm{I}_{2}$ concentration is high near the cathode current collector. To balance charge, the concentrations of the two anions $\left(\mathrm{I}^{-}\right.$and $\left.\mathrm{I}_{3}^{-}\right)$are highest where the cation $\left(\mathrm{Na}^{+}\right)$concentration is highest. Additionally, there is a coupled redistribution of the elemental iodine according to Eq. 37. The concentration of $\mathrm{I}_{2}$ is always much smaller than the other concentrations. If $\left[\mathrm{I}_{2}\right]$ becomes too large, then it cannot remain in solution and deleterious precipitation will occur.

Figure 5b shows profiles of the total elemental iodine concentration [I] and the ratio $\left[\mathrm{Na}^{+}\right] /[\mathrm{I}]$. Because iodine cannot leave the cathode compartment, the total [I] level within the catholyte remains fixed. In this example, it is fixed at $[\mathrm{I}]=8 \mathrm{M}$. Although the total elemental iodine is fixed, the spatial profiles of all the iodine-contains species can vary greatly. The ratio $\left[\mathrm{Na}^{+}\right] /[\mathrm{I}]$ is important because it indicates the propensity for precipitation. During charging (with $[\mathrm{I}]=8 \mathrm{M}$ ), the sodium concentration within the catholyte must be maintained as $\left[\mathrm{Na}^{+}\right] /[\mathrm{I}]>0.476$. As shown in Fig. $5 \mathrm{~b},\left[\mathrm{Na}^{+}\right] /[\mathrm{I}]$ has a local maximum in the interior of the cathode chamber, but is lowest in the vicinity of the cathode current collector.

Figure 5c shows spatial profiles of the exchange current density, ButlerVolmer charge-transfer rate, and the activation overpotential associated with 
Reaction 3. The overpotential $\eta_{\mathrm{c}}$ is highest near the cathode current collector, where the local charge-transfer rate $i_{\mathrm{BV}, \mathrm{e}}$ is also the highest. As is evident from Eq. 35, the exchange current density $i_{0}$ (Eq. 25) has a complicated dependence on the species concentrations.

Figure $5 \mathrm{~d}$ shows profiles of the equilibrium electric-potential difference $\left(E_{\mathrm{I}^{-} / \mathrm{I}_{2}}^{\mathrm{eq}}=\left(\Phi_{\mathrm{ed}}-\Phi_{\mathrm{el}}\right)^{\mathrm{eq}}\right)$, as well as the local electrostatic potentials of the electrode $\Phi_{\text {ed }}$ (Carbon felt) and electrolyte $\Phi_{\text {el }}$ (catholyte solution). Note that $E_{\mathrm{I}^{-} / \mathrm{I}_{2}}^{\mathrm{eq}}$ is positive (the negative is plotted), whereas both the electrostatic potentials are negative. The electrostatic-potential difference $\left(E=\Phi_{\mathrm{ed}}-\Phi_{\mathrm{el}}\right)$ is approximately $E=0.5 \mathrm{~V}$. Thus, during charging, the cathode's activation overpotential $\eta_{\mathrm{c}}$ (Eq. 26) has small positive values, as shown in Fig. 5c.

Throughout the charging processes, current is driven from the cathode current collector toward the NASICON membrane. Electronic current from the cathode current collector is transported throughout the porous electrode and is continuously converted into the ionic current within the catholyte solution by the charge-transfer reactions. Consequently, the electronic current density within the porous electrode decreases and ionic current density within the catholyte solution increases as net current travels from the cathode current collector to the NASICON membrane. The electrode electrostatic potential gradient $\nabla \Phi_{\text {ed }}$ decreases and electrolyte electrostatic potential gradient $\nabla \Phi_{\mathrm{el}}$ increases as a function of position between the NASICON and the cathode current collector (Fig. 5d).

\subsubsection{Charging, $S O C=0.94$}

Figure 6 shows the spatial profiles in the same format as Fig. 5, but near the end of the $1 \mathrm{C}$ charge cycle. Qualitatively, the profiles have similar shapes. 
However, the $\left[\mathrm{Na}^{+}\right] /[\mathrm{I}]$ profiles is important. At $\mathrm{SOC}=0.94$, near the cathode current collector $\left[\mathrm{Na}^{+}\right] /[\mathrm{I}]$ is approaching the $\mathrm{I}_{2}$ solubility limit. Thus, to avoid precipitation, the $1 \mathrm{C}$ charging is terminated before achieving full state of charge. Even in this state, the charging could continue to proceed, but at a lower rate.

If the $1 \mathrm{C}$ charging process was simply terminated at $\mathrm{SOC}=0.94$ and the battery was left at rest, then all the profiles would relax toward uniform distribution. The state of charge would remain at $\mathrm{SOC}=0.94$, but $\left[\mathrm{Na}^{+}\right] /[\mathrm{I}]$ would increase away from the precipitation limit. The charging process could resume without precipitation.

\subsubsection{Electrostatic potential differences}

The net electrostatic-potential differences across the cathode compartment for the electronic-conducting phase $\Delta \Phi_{\text {ed }}$ and ionic-conducting phase $\Delta \Phi_{\mathrm{el}}$ can be defined as the absolute value of the differences between the electrostatic potentials at the current-collector interface and the NASICON interface. At SOC $=0.5$ (Fig. 5), $\Delta \Phi_{\mathrm{ed}}=0.0351 \mathrm{~V}$ and $\Delta \Phi_{\mathrm{el}}=0.0365 \mathrm{~V}$. At $\mathrm{SOC}=0.94$ (Fig. 6), $\Delta \Phi_{\mathrm{ed}}=0.0357 \mathrm{~V}$ and $\Delta \Phi_{\mathrm{el}}=0.0639 \mathrm{~V} . \Delta \Phi_{\mathrm{ed}}$ in this case is essentially independent of the state-of-charge. However, as the battery charges, the ion concentrations within the catholyte decrease. As a result, based on the Nernst-Einstein relationship (Eq. 17), the electrolyte conductivity decreases. Thus, the polarization associated with ion transport increases as the battery charges. At $\mathrm{SOC}=0.94 \Delta \Phi_{\mathrm{el}}$ is nearly double what it is at $\mathrm{SOC}=0.5$. Comparing Figs. $5 \mathrm{c}$ and $6 \mathrm{c}$, at high $\mathrm{SOC}$ the local charge-transfer rates (i.e., $\left.i_{\mathrm{BV}, \mathrm{e}}\right)$ are somewhat higher near the cathode current collector and lower near the NASICON. Of course, at fixed charge rate 
(i.e., $1 \mathrm{C}$ ), the net charge-transfer rate (i.e., the integral of $\left.i_{\mathrm{BV}, \mathrm{e}}\right)$ must be the same independent of SOC. As discussed subsequently, the variations in $\Delta \Phi_{\mathrm{el}}$ play a more prominent role at higher charge and discharge rates.

[Figure 7 about here.]

[Figure 8 about here.]

\subsubsection{Discharging}

The dashed lines on Fig. 4 show cell voltage as a function of SOC and time for a cell that was initially fully charged with spatially uniform profiles (i.e., $\left.\mathrm{SOC}=1.0, \mathrm{E}_{\text {cell }}=3.05 \mathrm{~V}\right)$. Discharging at $1 \mathrm{C}$, the cell voltage decreases continuously to about $2.99 \mathrm{~V}$ at $\mathrm{SOC}=0.5$. The discharge terminates at $\mathrm{SOC}=0.025$ where the cell voltage is approximately $2.89 \mathrm{~V}$. The $1 \mathrm{C}$ discharge is terminated because the $\mathrm{Na}^{+}$concentration increases to the point that $\mathrm{NaI}$ precipitation would be initiated. Assuming that $1 \mathrm{C}$ charging begins immediately upon terminating the $1 \mathrm{C}$ discharge, the cell voltage immediately increases to $E_{\text {cell }}=3.09 \mathrm{~V}$. The subsequent $1 \mathrm{C}$ charging follows very closely the charging curve that resulted from an initially fully discharged state.

Fig. 7 shows spatial profiles at $\mathrm{SOC} \approx 0.5$ during the $1 \mathrm{C}$ discharge. Comparing Figs. 5 and 7, it is evident that the profiles are qualitatively different between charging and discharging. During discharge, $\mathrm{Na}^{+}$enters the catholyte from the NASICON, causing negative gradients for the $\mathrm{Na}^{+}$ concentration. Electrons enter from the cathode current collector and are conducted through carbon felt. To maintain charge neutrality, the anion $\left(\left[\mathrm{I}^{-}\right]\right.$and $\left.\left[\mathrm{I}_{3}^{-}\right]\right)$concentration gradients are also negative. The gradients of 
the total iodine $[\mathrm{I}]$ as well as the $\left[\mathrm{Na}^{+}\right] /[\mathrm{I}]$ are opposite to those in the charging process. Referring to Fig. 7c, note that the activation overpotentials and Butler-Volmer charge-transfer rates are both negative. A negative chargetransfer rate means that Reaction 3 is proceeding in the cathodic direction (i.e., consuming electrons). The electrostatic potentials $\Phi_{\text {ed }}$ and $\Phi_{\text {el }}$ both decrease from the NASICON interface toward the cathode current collector.

Figure 8 shows profiles during discharge, but at the near fully discharged state. The discharge is terminated at $\mathrm{SOC}=0.025$ to avoid precipitation. Comparing Figs. 7 and 8, it is evident that the profiles are qualitatively similar. Comparing Figs. $7 \mathrm{~d}$ and $8 \mathrm{~d}$, it can be seen that the electrolyte electrostatic potentials $\Phi_{\mathrm{el}}$ are different by approximately $100 \mathrm{mV}$ between $\mathrm{SOC}=0.5$ and $\mathrm{SOC}=0.025$. At $\mathrm{SOC}=0.025$ the $\mathrm{Na}^{+}$concentrations are high in the fully discharged state, causing the electrolyte conductivity to be high (Eq. 17). This, in turn, causes the catholyte electrostatic-potential gradients to be lower than that in the partially discharged state. In the fully discharged state the $\mathrm{Na}^{+}$is charge-balanced primarily by $\mathrm{I}^{-}$, with very low concentrations of $\mathrm{I}_{3}^{-}$.

Referring to Fig. 7, at $\mathrm{SOC}=0.5, \Delta \Phi_{\mathrm{ed}}=0.0401 \mathrm{~V}$ and $\Delta \Phi_{\mathrm{el}}=0.0283$ V. Referring to Fig. 8, SOC=0.025, $\Delta \Phi_{\mathrm{ed}}=0.0669 \mathrm{~V}$ and $\Delta \Phi_{\mathrm{el}}=0.0093$ $\mathrm{V}$. The charge-transfer process tends to be located in the regions nearer to the NASICON. At low SOC the electrons need to travel further through the carbon felt, causing $\Delta \Phi_{\text {ed }}$ to be larger at low SOC. However, $\Delta \Phi_{\text {el }}$ is relatively low at $\mathrm{SOC}=0.025$, which is caused by the high electrolyte conductivity and thus relatively low polarization associated with ionic current. 


\subsection{Effects of charge/discharge rates}

[Figure 9 about here.]

Continuing to consider the nominal battery layout and operating conditions, Fig. 9 illustrates the effects of the charge rate $(0.5 \mathrm{C}, 1.0 \mathrm{C}, 2.5 \mathrm{C}$, and $5.0 \mathrm{C})$. The current density is $44.9 \mathrm{~mA} \mathrm{~cm}^{-2}$ for $0.5 \mathrm{C}, 89.8 \mathrm{~mA} \mathrm{~cm}^{-2}$ for $1.0 \mathrm{C}, 224.6 \mathrm{~mA} \mathrm{~cm}^{-2}$ for $2.5 \mathrm{C}$, and $449.2 \mathrm{~mA} \mathrm{~cm}^{-2}$ for $5.0 \mathrm{C}$. The cell is initially set to be at the fully discharged state with the uniform species concentrations (Table 2). Figure 9a shows the cell voltage increases as the charge rate increases. To prevent precipitation, maximum achievable state of charge $\mathrm{SOC}_{\max }$ decreases significantly as the charging rate increases. Moreover, the time required to achieve the maximum SOC decreases as the charge rate increases. At $1 \mathrm{C}$, achieving $\mathrm{SOC}_{\max } \approx 0.94$ takes approximately 3384 s. At $5 \mathrm{C}$, achieving $\mathrm{SOC}_{\max } \approx 0.47$ takes approximately 338 s. Table 4 summarizes the $\mathrm{SOC}_{\max }$ and time to achieve maximum charge as functions of charge rate.

Figure $9 \mathrm{~b}$ shows $\Delta \Phi_{\mathrm{ed}}$ and $\Delta \Phi_{\mathrm{el}}$ as functions of SOC for different charge rates. The electrostatic-potential difference within the electron-conducting phase $\Delta \Phi_{\text {ed }}$ is highest at high charge rates, but is only weakly affected by the state of charge. By contrast, $\Delta \Phi_{\mathrm{el}}$ depends strongly on the charge rate and the state of charge. At the relatively low charge rates $(0.5 \mathrm{C}$ and $1 \mathrm{C}) \Delta \Phi_{\mathrm{el}}$ increases almost linearly as functions of the state of charge. At the relatively high charge rates $(2.5 \mathrm{C}$ and $5 \mathrm{C}), \Delta \Phi_{\mathrm{el}}$ increases rapidly in the approach to the maximum state of charge. At the high charge rates, the low $\mathrm{Na}^{+}$ diffusivity and concentration gradient limits the mobility of $\mathrm{Na}^{+}$transport toward the NASICON membrane. Consequently, very large electrostatic- 
potential gradients $\nabla \Phi_{\text {el }}$ are required to increase the ion-migration flux (cf., Eq. 5) to satisfy the imposed charge rate, which leads to rapid increase of $\Delta \Phi_{\mathrm{el}}$, and also $E_{\text {cell }}$.

4 to reach $\mathrm{SOC}_{\min }$ for different discharge rates.

Figure 10b shows that both $\Delta \Phi_{\mathrm{ed}}$ and $\Delta \Phi_{\mathrm{el}}$ increase as the discharge rate increases. For each discharge rate, $\Delta \Phi_{\mathrm{el}}$ continuously decreases as the cell becomes more discharged. The gradient $\nabla \Phi_{\mathrm{el}}$ increases at the high discharge rates. At the high discharge rates the high $\mathrm{Na}^{+}$flux that enters the catholyte solution from the NASICON leads to large species concentration gradients near the NASICON membrane. Because of transport limitations, ionic species concentrations are relatively high near the NASICON, leading to relatively high local electrolyte conductivities. As a consequence, the magnitudes of the gradients $\nabla \Phi_{\text {el }}$ remain relatively low. Nevertheless, the 
solubility limit of NaI near the NASICON limits the discharge. Figure 10b shows that $\Delta \Phi_{\text {ed }}$ slightly increases as SOC decreases due to the shift of local charge-transfer rate toward the region near the NASICON. The steep asymptotic behavior that is evident in high-rate charging (Fig. 9) is not present in as the discharge reaches the limits.

\subsection{Effect of catholyte concentrations}

The total elemental iodine loading greatly affects the ion concentrations and the solubility limits (Table 2). Figure 11 shows how the iodine loading affects the charge process. In all cases shown the charge rate is fixed at $i_{\mathrm{ex}}=100 \mathrm{~mA} \mathrm{~cm}-2$ and the operating temperature is $120^{\circ} \mathrm{C}$. The charging process begins from the equilibrium fully discharged condition.

[Table 5 about here.]

As the elemental iodine loading increases, the ion concentrations within the catholyte solution increase, leading to higher electrolyte conductivity (Eq. 17). As a result $\Delta \Phi_{\mathrm{el}}$ decreases at high iodine loadings. Thus, lower cell potentials $E_{\text {cell }}$ required to charge the battery with higher iodine (Fig. 11a). Figure 11a also shows that $\mathrm{SOC}_{\max }$ is about 0.74 at $[\mathrm{I}]=4 \mathrm{M}$, and increases to about 0.94 at $[\mathrm{I}]=8.0 \mathrm{M}$. Table 5 summarizes $\mathrm{SOC}_{\max }$ and the required charging times.

[Figure 11 about here.]

[Figure 12 about here.] 
Figure 12 shows discharge characteristics as functions of SOC for the four elemental iodine concentrations. As the iodine loading increases, the electrostatic-potential differences $\Delta \Phi_{\text {ed }}$ and $\Delta \Phi_{\text {el }}$ increase by less than $0.1 \mathrm{~V}$. As a result $E_{\text {cell }}$ decreases only very slightly as the iodine loading increases. However, $\mathrm{SOC}_{\min }$ increases significantly from the being able to fully discharge at $[\mathrm{I}]=4.0 \mathrm{M}$ to about 0.37 at $[\mathrm{I}]=10.0 \mathrm{M}$. Table 5 summarizes the $\mathrm{SOC}_{\min }$ and the discharge times as functions of the iodine loading.

\subsection{Effect of cathode conductivity}

The conductivity of porous electrode felt depends on the porosity and the mechanical compression (Eq. 24). The electrode conductivity can vary from $10 \mathrm{~S} \mathrm{~m}^{-1}$ at no mechanical compression to about $500 \mathrm{~S} \mathrm{~m}^{-1}$ at large mechanical compression. Considering four electrode conductivities and a charge rate of 1C, Fig. 13 shows cell voltages and electrostatic-potential differences as functions of SOC during charging. In all cases, the porosity is fixed as $\phi=0.8$. As the electrode conductivity decreases, the resistance for the electron transport through the porous cathode felt increases, causing $\Delta \Phi_{\text {ed }}$ to increase (Fig. 13b). The charge-transfer processes are localized near the cathode current collector, which leads to the increases of $\Delta \Phi_{\mathrm{el}}$ as the ion flux needs must travel further to reach the NASICON. The high concentration of $\mathrm{I}_{2}$ at the interface with the cathode current collector limits the maximum achievable state of charge. With $\sigma_{\mathrm{ed}}=10 \mathrm{~S} \mathrm{~m}^{-1}, \mathrm{SOC}_{\max } \approx 0.54$ (Fig. 13a). At the nominal $\sigma_{\text {ed }}=100 \mathrm{~S} \mathrm{~m}^{-1}, \mathrm{SOC}_{\max } \approx 0.94$.

[Figure 13 about here.]

[Figure 14 about here.] 
Figure 14 shows cell potentials during 1C discharge, with four different electrode conductivities. Decreasing cathode conductivity leads to increased polarization and lower cell voltages. At full charge the cell voltage is $E_{\text {cell }} \approx$ $3.06 \mathrm{~V}$ when $\sigma_{\text {ed }}=200 \mathrm{~S} \mathrm{~m}^{-1}$, but is reduced to about $2.96 \mathrm{~V}$ when $\sigma_{\text {ed }}=10$ $\mathrm{S} \mathrm{m}^{-1}$. The very low electrode conductivity of $10 \mathrm{~S} \mathrm{~m}^{-1}$ is actually smaller than the electrolyte conductivity. Under this assumption the charge-transfer processes within the cathode moves closer to the cathode current collector such that the electronic current travels shorter distance to reach the current collector. As $\mathrm{I}_{3}^{-}$and $\mathrm{I}_{2}$ in the region near to the cathode current collector are fully discharged into $\mathrm{I}^{-}$, the charge-transfer processes move away from the current collector and the electronic current must travel further to reach the cathode current collector. This, in turn, causes $\Delta \Phi_{\text {ed }}$ to increase (Fig. 14b) and large decreases in cell voltage (Fig. 14a). Low electrode conductivity also leads to early termination of the discharge processes. Assuming $\sigma_{\text {ed }}=10 \mathrm{~S}$ $\mathrm{m}^{-1}, \mathrm{SOC}_{\min } \approx 0.57$.

\section{Summary and conclusions}

A new computational model is derived and applied to predict performance of a Na- $\mathrm{I}_{2}$ rechargeable battery. A molten-sodium anode is separated by a NASICON membrane from a porous-carbon cathode that is infiltrated with an aqueous catholyte. The NASICON is a pure Na-ion conductor. Using a Nernst-Planck formulation, the model considers the transport of four mobile species $\left(\mathrm{Na}^{+}, \mathrm{I}^{-}, \mathrm{I}_{3}^{-}\right.$and $\left.\mathrm{I}_{2}\right)$ within the catholyte. A ButlerVolmer formulation is used to represent the charge-transfer chemistry at the interface between the molten sodium and the NASICON and at the interfaces 
between the porous-carbon cathode and the catholyte solution. Overall, the chemistry can be represented as $2 \mathrm{Na}^{+}+2 \mathrm{I}^{-} \rightleftharpoons 2 \mathrm{Na}+\mathrm{I}_{2}$. However, the cathode chemistry is more complex, including iodine redistribution between $\mathrm{I}^{-}, \mathrm{I}_{3}^{-}$and $\mathrm{I}_{2}$. The model considers the solubility of $\mathrm{NaI}$ and $\mathrm{I}_{2}$ within the catholyte. Depending on the charge or discharge rate, catholyte solubility limits the state-of-charge that can be achieved. The model predicts the effects of charge/discharge rates, iodine concentrations, and electrode conductivities on battery performance.

\section{Acknowledgments}

This research was supported by the US Department of Energy, Office of Electricity (Dr. Imre Gyuk, Program manager), via a subcontract with Sandia National Laboratories. It was also partially supported by the Office of Naval Research via grant N00014-08-1-0539. We gratefully acknowledge insightful and helpful discussions with Dr. Sai Bhavaraju (Ceramatec, Inc.), Prof. Jason Porter (CSM), and Dr. David Ingersoll (Sandia National Laboratories).

\section{References}

\section{References}

[1] Y.L. Wang, Q.L. Sun, Q.Q. Zhao, J.S. Cao, and S.H. Ye. Rechargeable lithium/iodine battery with superior high-rate capability by using iodine-carbon composite as cathode. Energy Environ. Sci., 4:3947-3950, 2011. 
[2] Y. Zhao, L. Wang, and H.R. Byon. High-performance rechargeable lithium-iodine batteries using triiodide/iodide redox couples in an aqueous cathode. Nature Comm., 4:1896, 2013.

[3] Y. Zhao, M. Hong, N.B. Mercier, G. Yu, H.C. Choi, and H.R. Byon. A $3.5 \mathrm{~V}$ lithium-iodine hybrid redox battery with vertically aligned carbon nanotube current collector. Nana Lett., 14:1085-1092, 2014.

[4] Q. Zhao, Y. Lu, Z. Zhu, Z. Tao, and J. Chen. Rechargeable lithiumiodine batteries with iodine/nanoporous carbon cathode. Nano Lett., 15:5982-5987, 2015.

[5] Y. Zhao and H.R. Byon. High-performance lithium-iodine flow battery. Adv. Energy Mater., 3:1630-1635, 2013.

[6] Y. Zhao, Y. Ding, Y. Li, L. Peng, H.R. Byon, J.B. Goodenough, and G. Yu. A chemistry and material perspective on lithium redox flow batteries towards high-density electrical energy storage. Chem. Soc. Rev., 44:7968-7996, 2015.

[7] A. Anderko and M.M. Lencka. Computation of electrical conductivity of multicomponent aqueous systems in wide concentration and temperature ranges. Ind. Eng. Chem. Res,., 36:1932-1943, 1997.

[8] A. Anderko and M.M. Lencka. Modeling self-diffusion in multicomponent aqueous electrolyte systems in wide concentration ranges. Ind. Eng. Chem. Res,., 37:2878-2888, 1998. 
[9] J.T.R. Watson, R.S. Basu, and J.V. Sengers. An improved representative equation for the dynamic viscosity of water substance. J. Phys. Chem. Ref. Data, 9:1255-1290, 1980.

[10] L. Cantrel, R. Chaouche, and J. Chopin-Dumas. Diffusion coefficients of molecular iodine in aqueous solutions. J. Chem. Eng. Data, 42:216-220, 1997.

[11] L. Cantrel, J.M. Fulconis, and J.Chopin-Dumas. Voltammetric analysis of iodide and diffusion coefficients between 25 and $85{ }^{\circ} \mathrm{C}$. J. Solution Chem., 27:373-393, 1998.

[12] A. Hayashi, K. Noi, A. Sakuda, and M. Tatsumisago. Superionic glassceramic electrolytes for room-temperature rechargeable sodium batteries. Nat. Commun., 3:856-860, 2012.

[13] H. Zhu, S. Bhavaraju, and R.J. Kee. Computational model of a sodiumcopper-iodide rechargeable battery. Electrochim. Acta, 112:629639, 2013.

[14] M.H. Chakrabarti, N.P. Brandon, S.A. Hajimolana, F. Tariq, V. Yufit, M.A. Hashim, M.A. Hussain, C.T.J. Low, and P.V. Aravind. Application of carbon materials in redox flow batteries. J. Power Sources, 153:150166, 2014.

[15] R. Carta, S. Palmas, A.M. Polcaro, and G. Tola. Behaviour of a carbon felt flow by electrodes. Part I: Mass transfer characteristics. J. Appl. Electrochem., 21:793-798, 1991.

[16] C. Oloman, M. Matte, and C. Lum. Electronic conductivity of graphite fiber fixed-bed electrodes. J. Electrochem. Soc., 138:2330-2334, 1991. 
[17] W.G. Bessler, J. Warnatz, and D.G. Goodwin. The influence of equilibrium potential on the hydrogen oxidation kinetics of SOFC anodes. Solid State Ionics, 177:3371-3383, 2007.

[18] R.J. Kee, H. Zhu, R.J. Braun, and T.L. Vincent. Modeling the steadystate and dynamic characteristics of solid-oxide fuel cells. Adv. in Chem. Engr., 41:331-381, 2012.

[19] G. Boschloo and A. Hagfeldt. Characteristics of the iodide/triiodide redox mediator in dye-sensitized solar cells. Acc. Chem. Res., 42:18191826, 2009.

[20] L.M. Dané, L.J.J. Janssen, and J.G. Hoogland. The iodine/iodide redox couple at a platinum electrode. Electrochim. Acta, 13:507518, 1968.

[21] K.J. Hanson and C.W. Tobias. Electrochemistry of iodide in propylene carbonate. I. cyclic voltammetry monitored by optical spectroscopy. J. Electrochem. Soc., 134:2204-2210, 1987.

[22] C.L. Bentley, A.M. Bond, A.F. Hollenkamp, P.J. Mahon, and J. Zhang. Voltammetric determination of the iodide/iodine formal potential and triiodide stability constant in conventional and ionic liquid media. $J$. Phys. Chem. C, 119:22392-22403, 2015.

[23] H.S. Wroblowa and S. Saunders. Flow through electrodes. II. The $\mathrm{I}_{3}^{-} / \mathrm{I}^{-}$ redox couple. Electroanal. Chem. Interfac. Electrochem., 42:329-346, 1973.

[24] T.R. Briggs and W.F. Geigle. Note on the system sodium iodide--water. J. Phys. Chem., 44:373-377, 1940. 
[25] R.T. Iwamoto. Solvent effects on the electro-oxidation of iodide ion. Anal. Chem., 31:955-955, 1959.

[26] D.A. Palmer, R.W. Ramette, and R.E. Mesmer. Triiodidie ion formation equilibrium and activity coefficients in aqueous solution. J. Solution Chem., 13:673-683, 1984.

[27] M. Davies and E. Gwynne. The iodineiodide interaction. J. Am. Chem. Soc., 74:27482752, 1952.

[28] R.W. Ramette and R.W. Sandford Jr. Thermodynamics of iodine solubility and triiodide ion formation in water and in deuterium oxide. $J$. Am. Chem. Soc., 87:5001-505, 1965.

[29] D.A. Palmer, R.W. Ramette, and R.E. Mesmer. The hydrolysis of iodine: equilibria at high temperatures. J. Nuclear Mater., 130:280-286, 1985.

[30] H. Guo, P. Zhang, S. Chen, L. Wang, and J. Xu. Review of thermodynamic properties of the components in HI decomposition section of the iodine-sulfur process. Inter. J. Hydrogen Energy, 36:9505-9513, 2011.

[31] R.R. Pawar, C.S. Aher, J.D. Pagar, S.L. Nikam, and M. Hasan. Solubility, density and solution thermodynamics of $\mathrm{NaI}$ in different pure solvents and binary mixtures. J. Chem. Eng. Data, 57:3563-3572, 2012.

[32] A. Seidell. Solubilities of Inorganic and Organic Substances. D. Van Nostrand Company, New York, 1919. 
784

785

[33] S.W. Goldstein. The iodide-iodine solubility relation. J. Am. Pharm. Assoc., 41:333-335, 1952.

[34] U.M. Ascher and L.R. Petzold. Computer methods for ordinary differential equations and differential-algebraic equations. SIAM, Philadelphia, PA, 1998.

[35] R.J. Kee, M.E. Coltrin, and P. Glarborg. Chemically reacting flow: Theory and practice. Wiley, Hoboken, NJ, 2003.

[36] P. Deufhard, E. Hairer, and J. Zugck. One-step and extrapolation methods for differential-algebraic systems. Numer. Math., 51:501-516, 1987. 


\section{List of Figures}

1 Illustration of the salient aspects of a Na- $\mathrm{I}_{2}$ secondary battery. 41

2 Illustration of the governing equations, computational domains, and boundary conditions. As illustrated, the arrows indicate discharge directions. . . . . . . . . . . . . . . . . 42

3 Boiling temperature of the aqueous $\mathrm{NaI}$ solution as a function of $\mathrm{NaI}$ weight percentage in water. . . . . . . . . . . . . . 43

4 Cell voltages as functions of a) the state of charge (SOC) and b) time during the first $1 \mathrm{C}$ charge and discharge cycles. Assuming a total iodine concentration of $[\mathrm{I}]=8 \mathrm{M}$, the initial molar concentrations at the fully charge and fully discharged conditions are found in Table 2. The solid lines shows the behavior when the cell is charged initially from the fully discharged state. The dashed lines show the behavior when the cell is discharged initially from the fully charged state. The "star" symbols indicate conditions where Figs. 5-8 show predicted species and electrostatic-potential profiles. . . . . . . . 44

5 Model-predicted profiles within the cathode compartment dur-

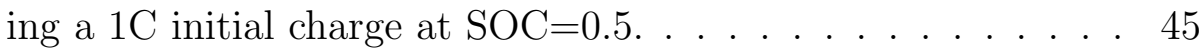

6 Model-predicted profiles within the cathode compartment dur-

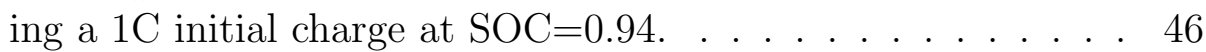

$7 \quad$ Model-predicted profiles within the cathode compartment dur-

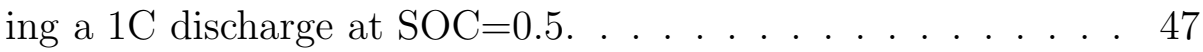

8 Model-predicted profiles within the cathode compartment during a $1 \mathrm{C}$ discharge at $\mathrm{SOC}=0.025 \ldots$. . . . . . . . . . . . 48

9 Comparison of the cell voltage and electrostatic potential differences $\left(\Delta \Phi_{\mathrm{ed}}\right.$ and $\Delta \Phi_{\mathrm{el}}$ within the cathode as functions of the state of charge during charging at four rates $(0.5 \mathrm{C}, 1.0 \mathrm{C}$, 2.5C, and 5.0C). . . . . . . . . . . . . . . . . 49

10 Comparison of the cell voltage and electrostatic potential differences $\left(\Delta \Phi_{\mathrm{ed}}\right.$ and $\Delta \Phi_{\mathrm{el}}$ within the cathode as functions of the state of charge during discharge at four rates $(0.5 \mathrm{C}, 1.0 \mathrm{C}$, 2.5C, and 5.0C) . . . . . . . . . . . . . . 50

11 Comparison of the cell voltage and electrostatic potential differences $\left(\Delta \Phi_{\text {ed }}\right.$ and $\Delta \Phi_{\text {el }}$ within the cathode as functions of the state of charge during fixed-rate charging $\left(i_{\mathrm{ex}}=100 \mathrm{~mA}\right.$ $\left.\mathrm{cm}^{-2}\right)$ at four elemental iodine loadings $([\mathrm{I}]=4,6,8$, and $10 \mathrm{M}) .51$ 
12 Comparison of the cell voltage and electrostatic potential differences $\left(\Delta \Phi_{\mathrm{ed}}\right.$ and $\Delta \Phi_{\mathrm{el}}$ within the cathode as functions of the state of charge during fixed-rate discharging $\left(i_{\mathrm{ex}}=100\right.$ $\left.\mathrm{mA} \mathrm{cm}{ }^{-2}\right)$ at four elemental iodine loadings $([\mathrm{I}]=4,6,8$, and $10 \mathrm{M}) . \ldots \ldots \ldots \ldots 2$

13 Comparison of the cell voltage and electrostatic potential differences $\left(\Delta \Phi_{\mathrm{ed}}\right.$ and $\Delta \Phi_{\mathrm{el}}$ within the cathode as functions of the state of charge during $1 \mathrm{C}$ fixed-rate charging at four electrode conductivities $\left(\sigma_{\text {ed }}=10,50,100,200 \mathrm{~S} \mathrm{~m}^{-1}\right) \ldots \ldots . . . . .53$

14 Comparison of the cell voltage and electrostatic potential differences $\left(\Delta \Phi_{\mathrm{ed}}\right.$ and $\Delta \Phi_{\mathrm{el}}$ within the cathode as functions of the state of charge during $1 \mathrm{C}$ fixed-rate discharging at four electrode conductivities $\left(\sigma_{\text {ed }}=10,50,100,200 \mathrm{~S} \mathrm{~m}^{-1}\right) \ldots$. . . 54 


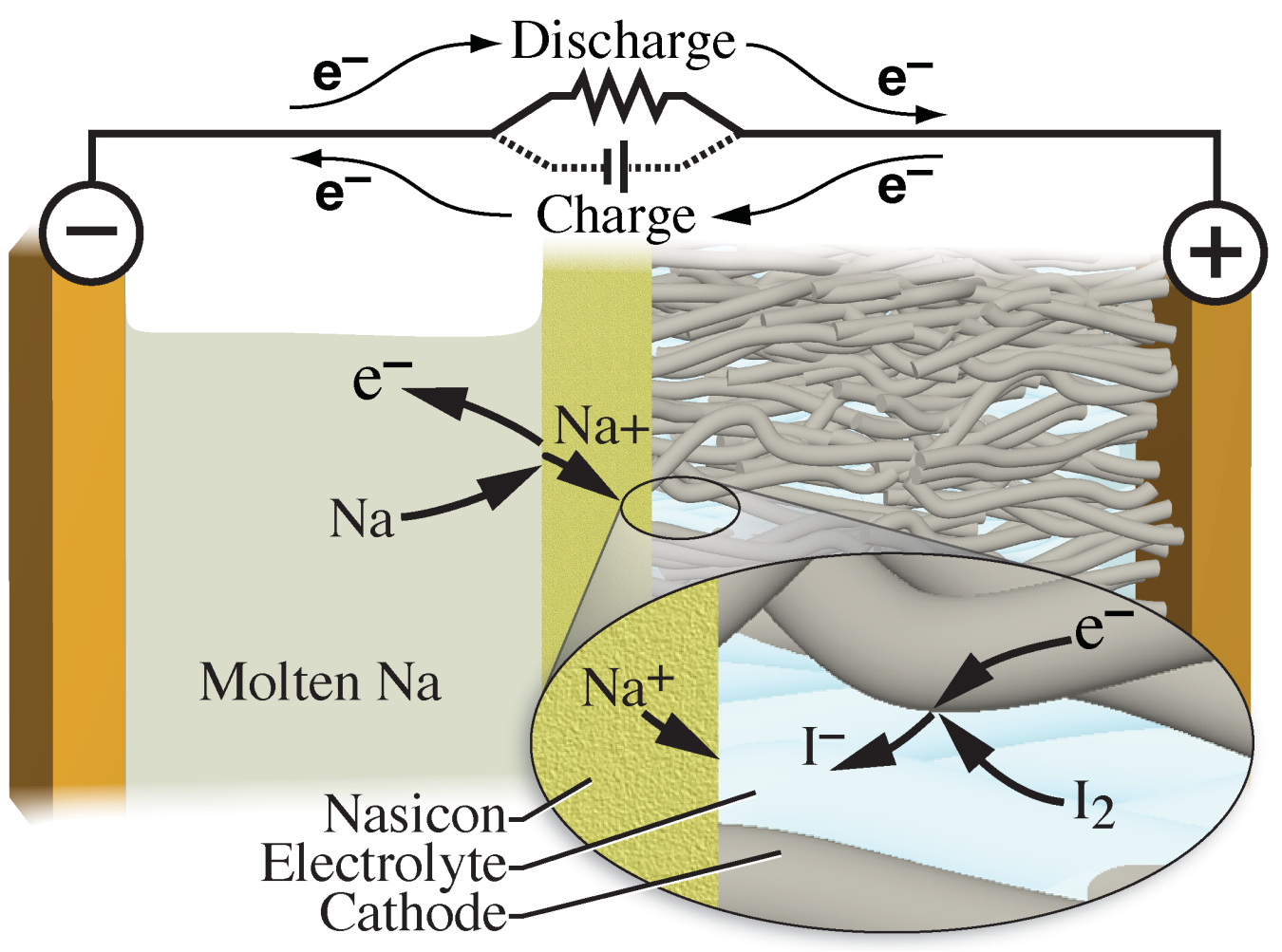

Figure 1: Illustration of the salient aspects of a Na- $\mathrm{I}_{2}$ secondary battery. 


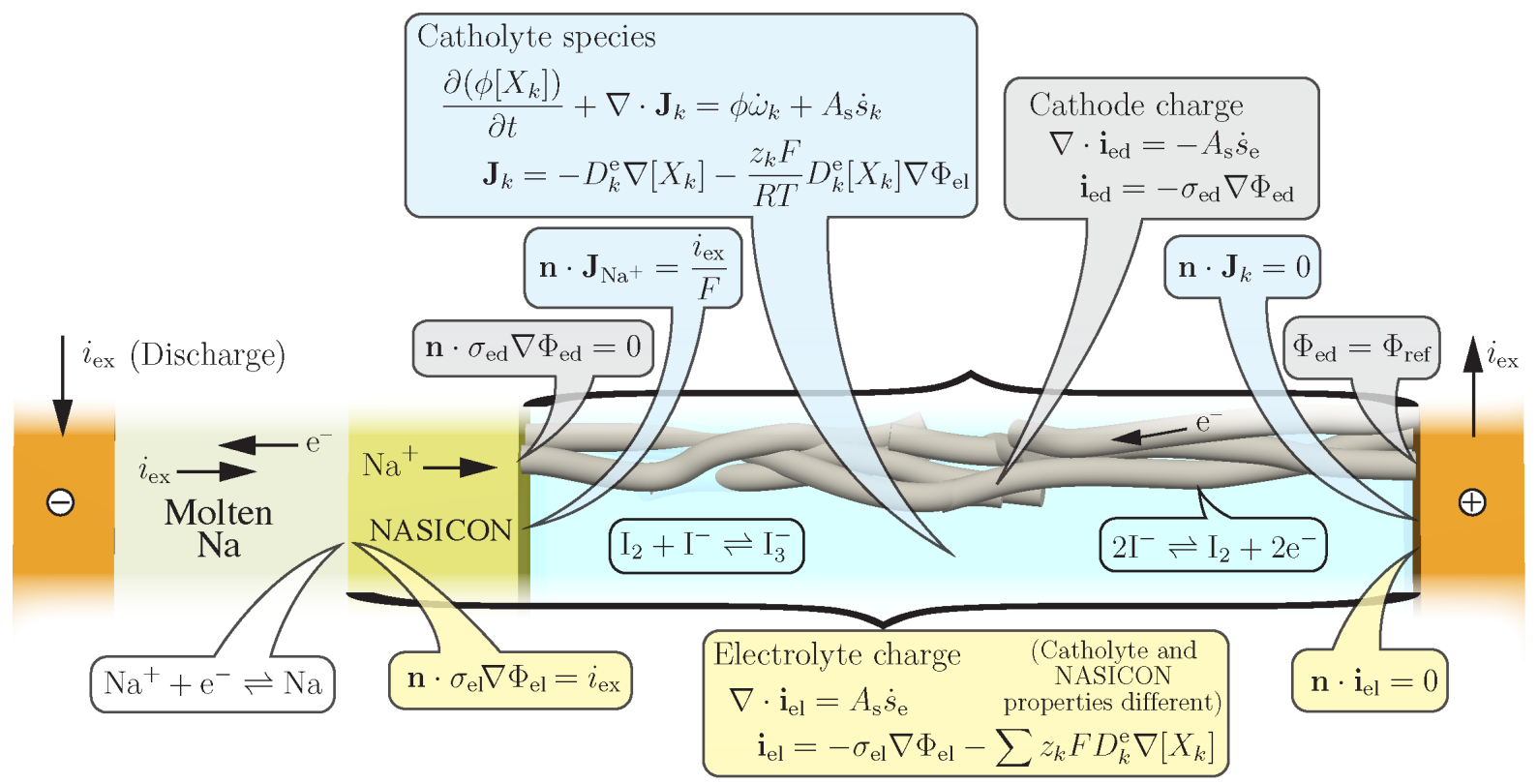

Figure 2: Illustration of the governing equations, computational domains, and boundary conditions. As illustrated, the arrows indicate discharge directions. 


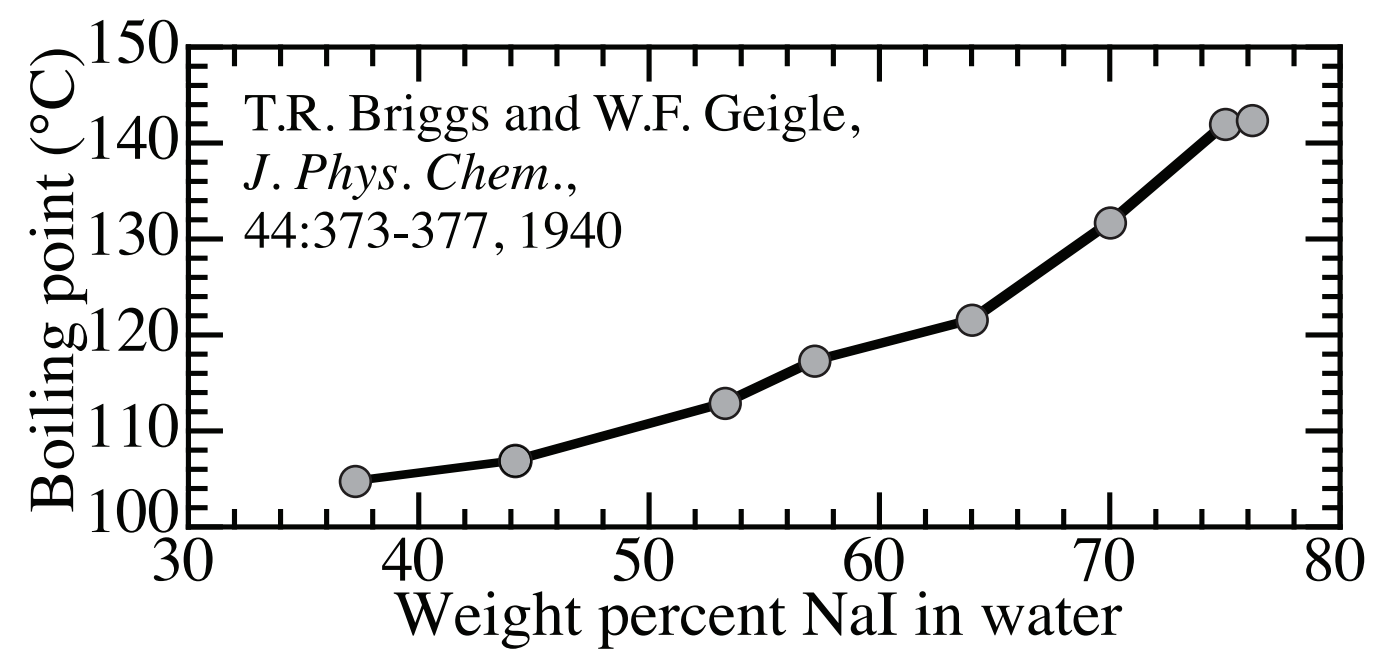

Figure 3: Boiling temperature of the aqueous $\mathrm{NaI}$ solution as a function of $\mathrm{NaI}$ weight percentage in water. 

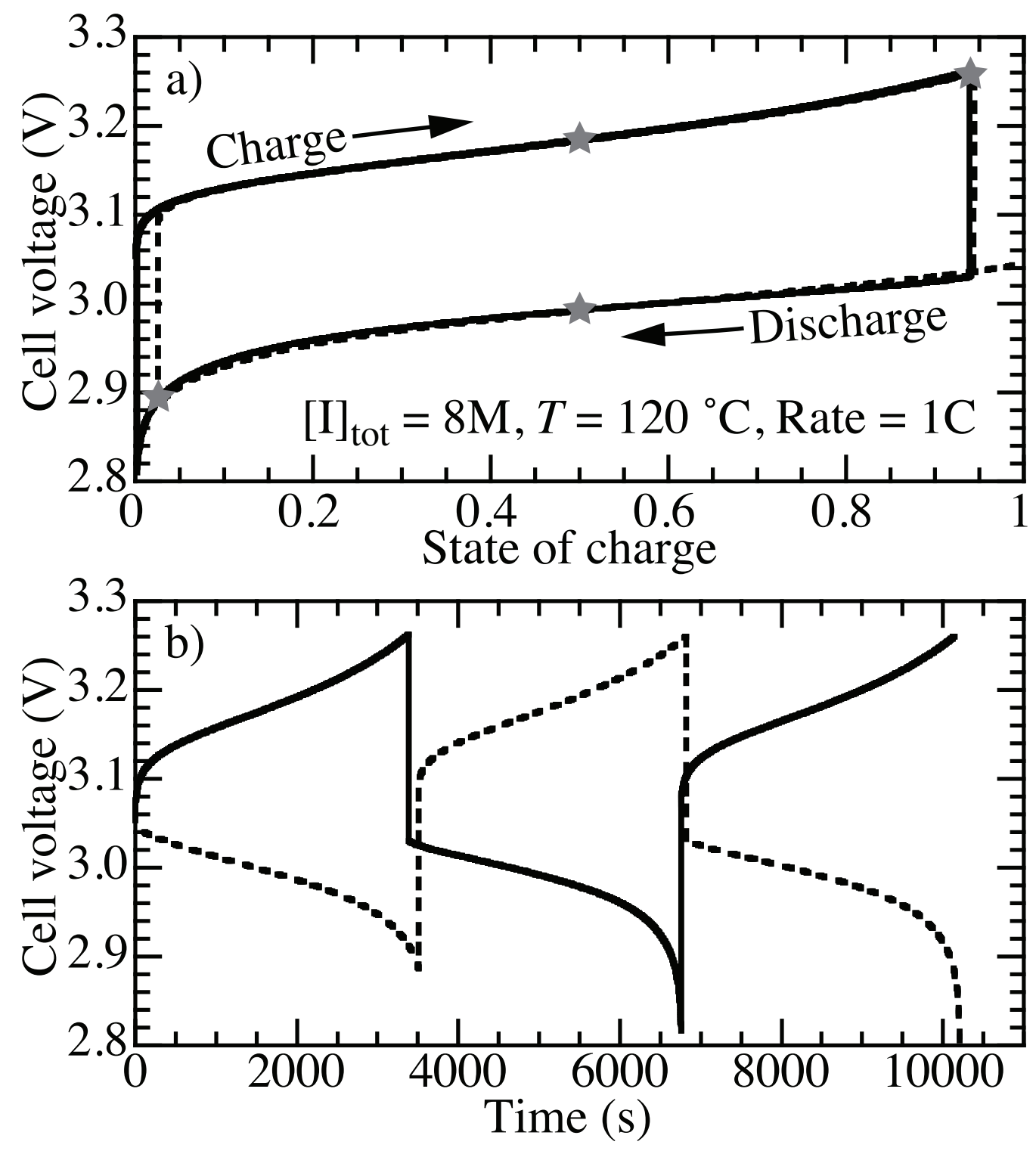

Figure 4: Cell voltages as functions of a) the state of charge (SOC) and b) time during the first $1 \mathrm{C}$ charge and discharge cycles. Assuming a total iodine concentration of $[\mathrm{I}]=8$ $\mathrm{M}$, the initial molar concentrations at the fully charge and fully discharged conditions are found in Table 2. The solid lines shows the behavior when the cell is charged initially from the fully discharged state. The dashed lines show the behavior when the cell is discharged initially from the fully charged state. The "star" symbols indicate conditions where Figs. 5-8 show predicted species and electrostatic-potential profiles. 


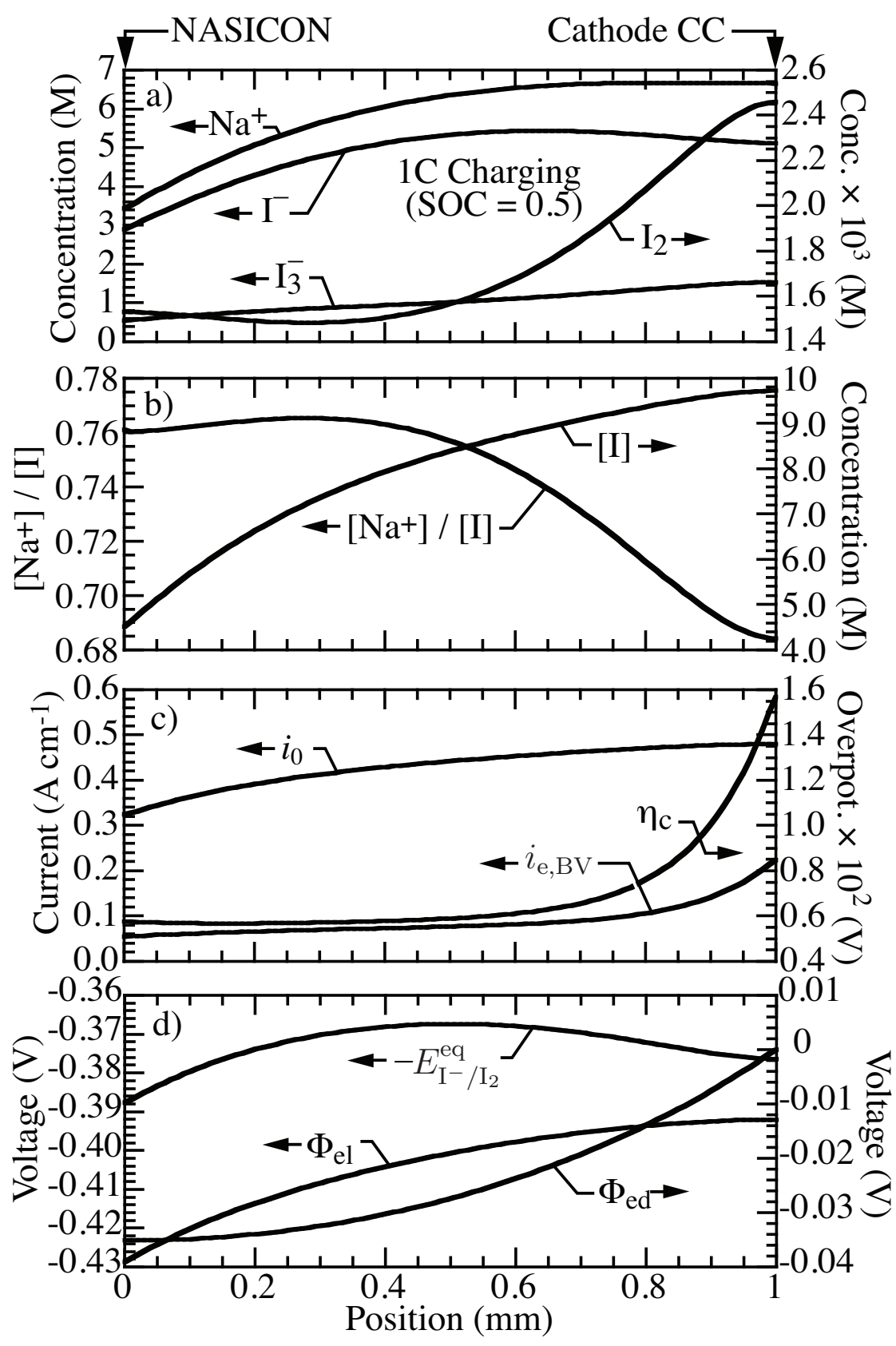

Figure 5: Model-predicted profiles within the cathode compartment during a $1 \mathrm{C}$ initial charge at $\mathrm{SOC}=0.5$. 

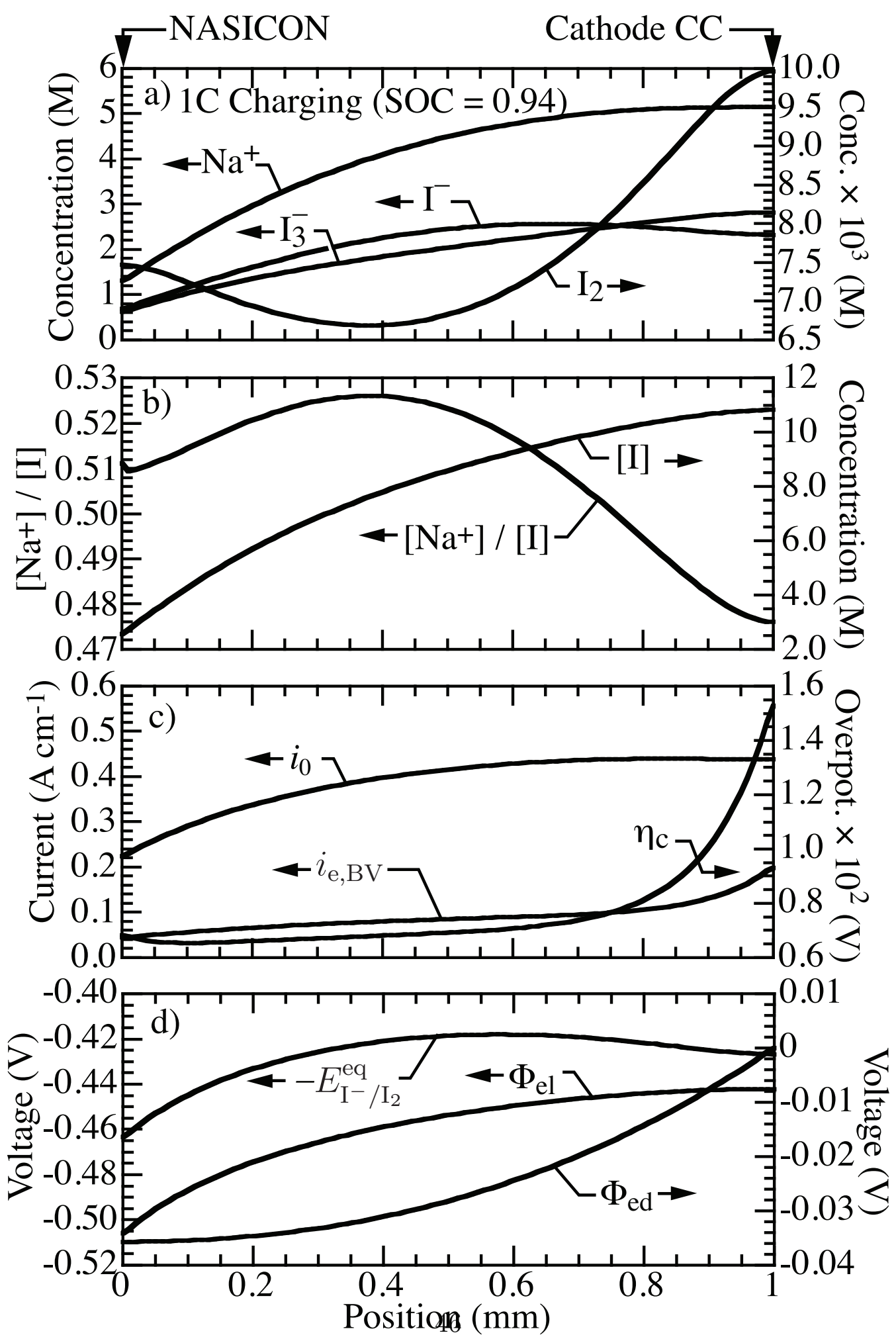

Figure 6: Model-predicted profiles within the cathode compartment during a 1C initial charge at $\mathrm{SOC}=0.94$. 

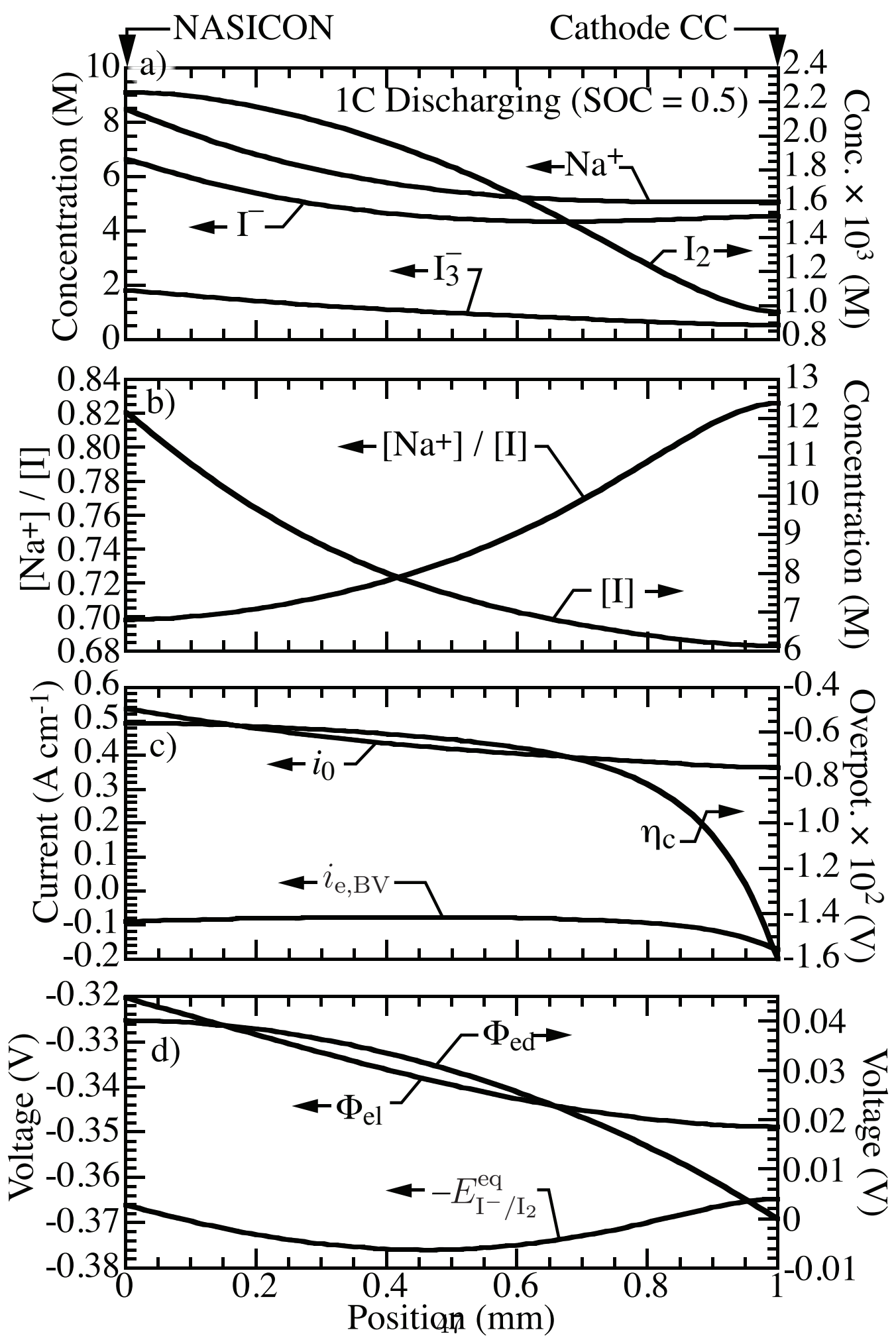

Figure 7: Model-predicted profiles within the cathode compartment during a 1C discharge at $\mathrm{SOC}=0.5$. 

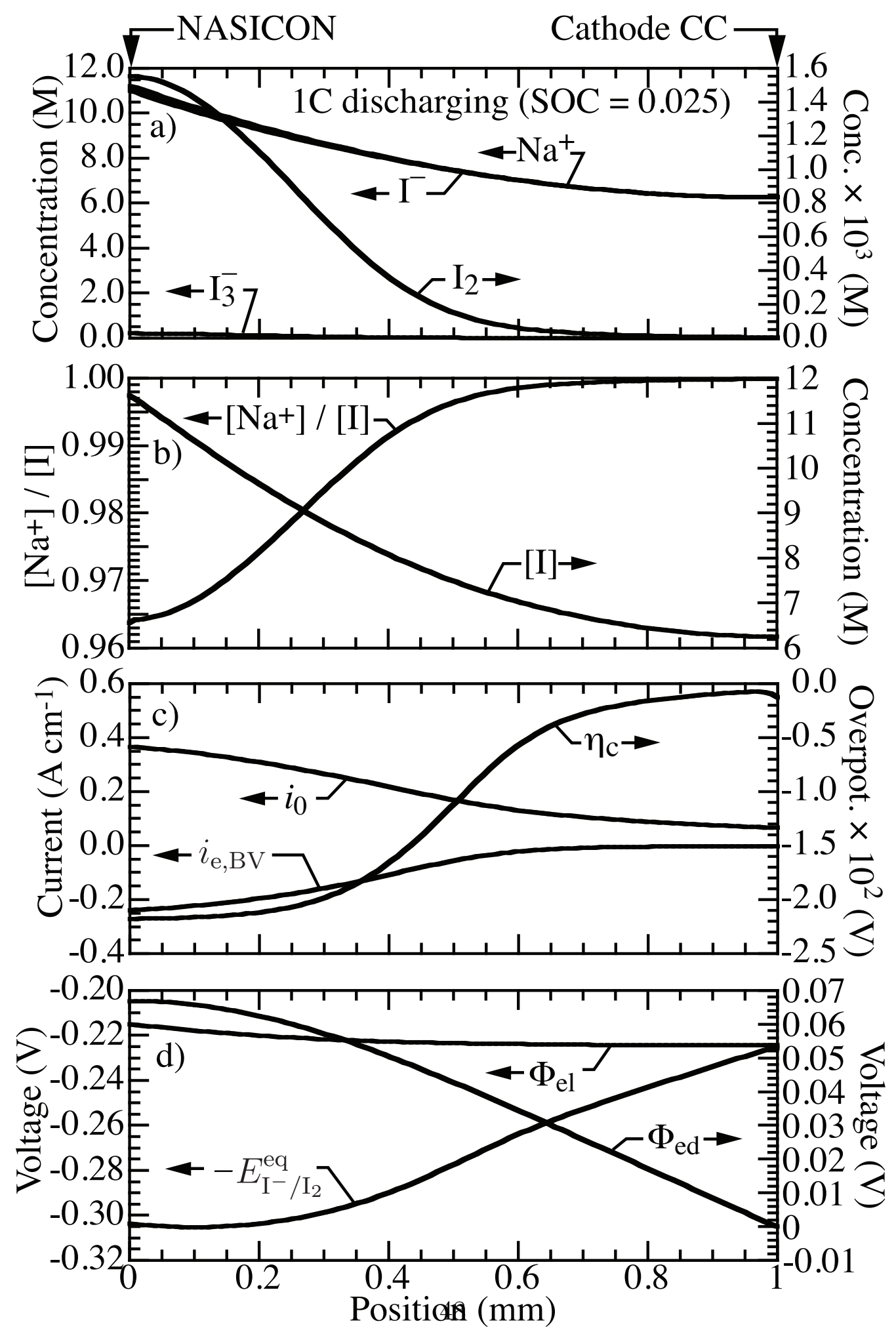

Figure 8: Model-predicted profiles within the cathode compartment during a 1C discharge at $\mathrm{SOC}=0.025$. 

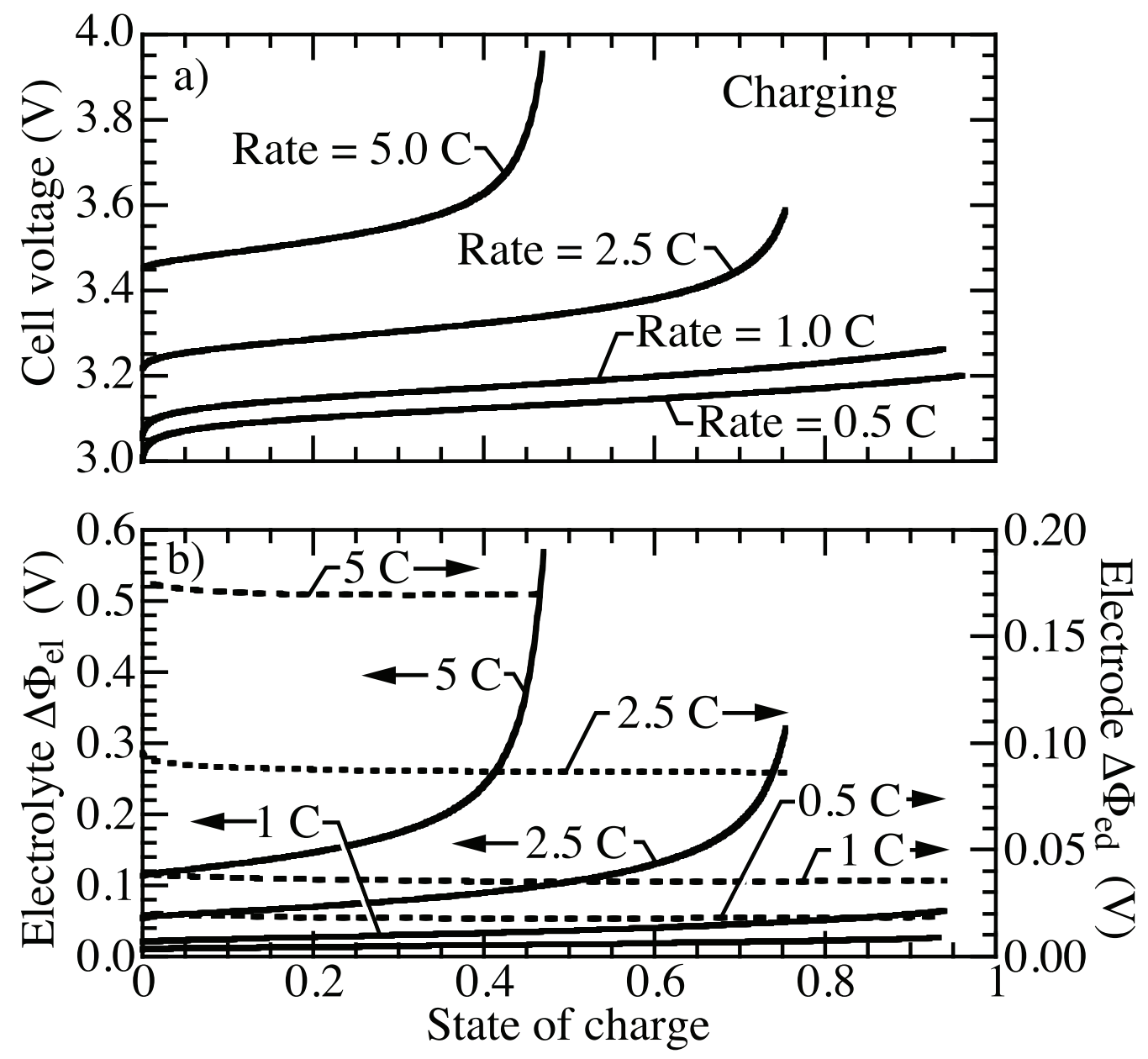

Figure 9: Comparison of the cell voltage and electrostatic potential differences $\left(\Delta \Phi_{\text {ed }}\right.$ and $\Delta \Phi_{\mathrm{el}}$ within the cathode as functions of the state of charge during charging at four rates $(0.5 \mathrm{C}, 1.0 \mathrm{C}, 2.5 \mathrm{C}$, and $5.0 \mathrm{C})$. 


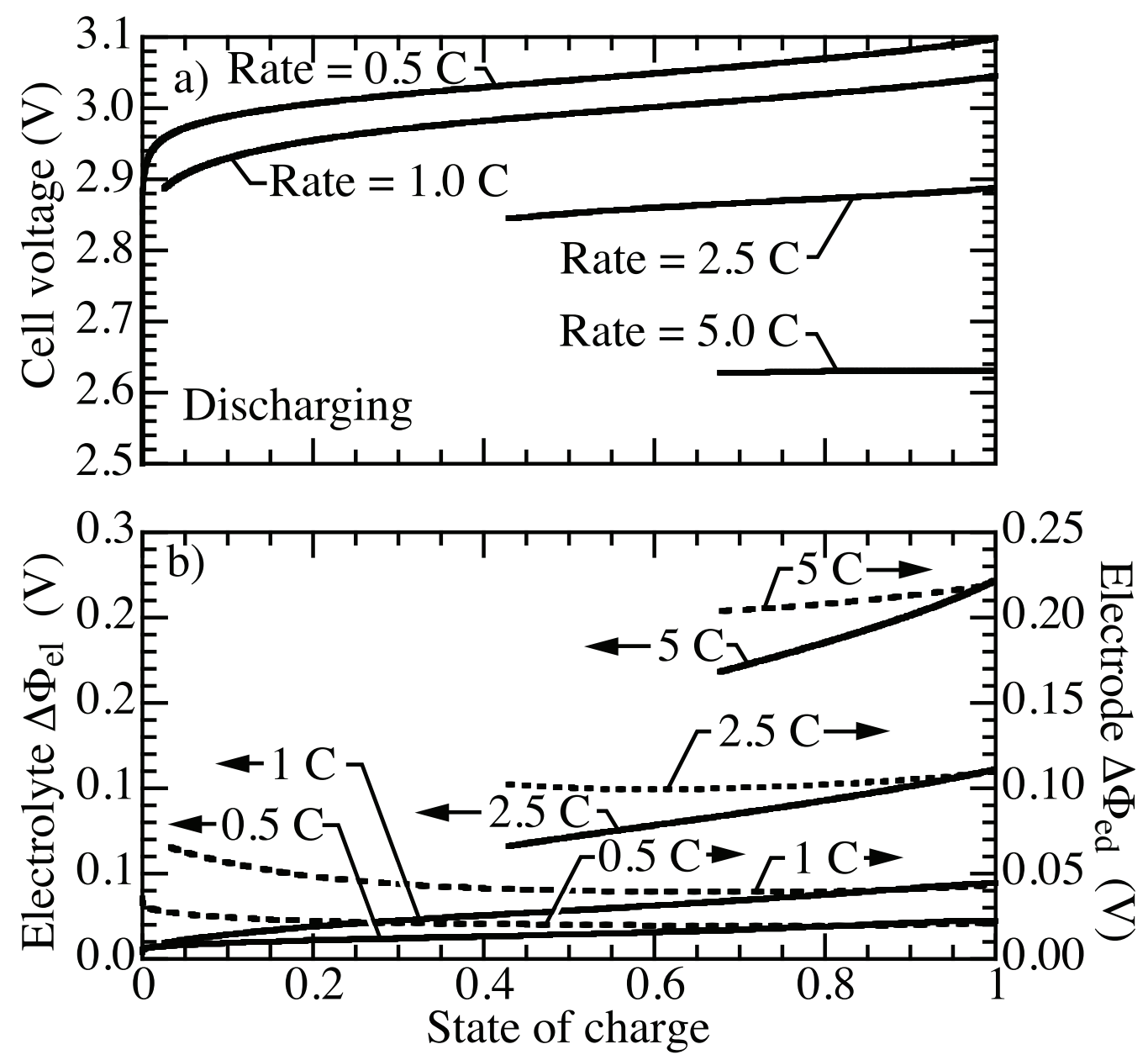

Figure 10: Comparison of the cell voltage and electrostatic potential differences $\left(\Delta \Phi_{\text {ed }}\right.$ and $\Delta \Phi_{\mathrm{el}}$ within the cathode as functions of the state of charge during discharge at four rates $(0.5 \mathrm{C}, 1.0 \mathrm{C}, 2.5 \mathrm{C}$, and $5.0 \mathrm{C})$. 

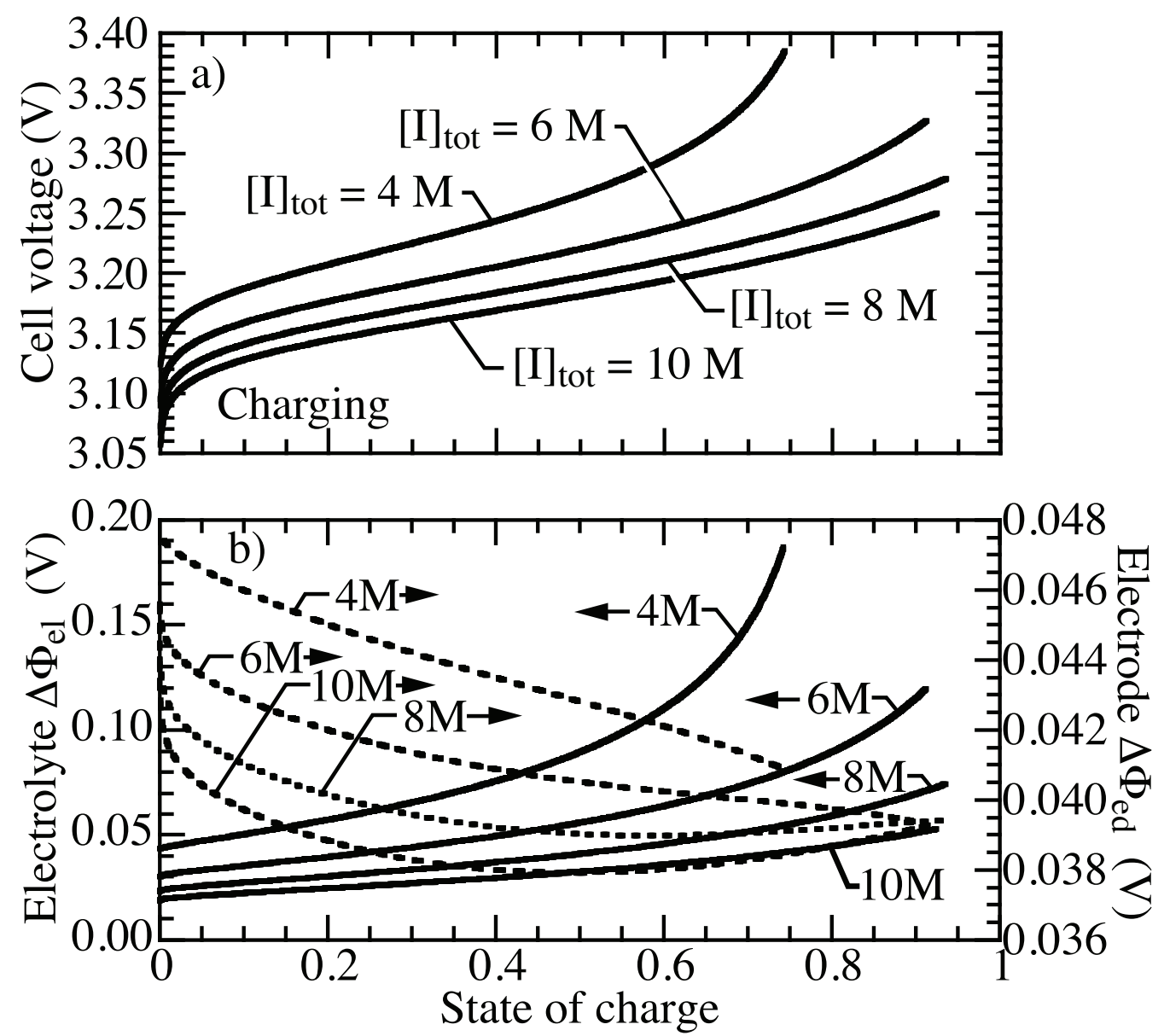

Figure 11: Comparison of the cell voltage and electrostatic potential differences $\left(\Delta \Phi_{\text {ed }}\right.$ and $\Delta \Phi_{\mathrm{el}}$ within the cathode as functions of the state of charge during fixed-rate charging $\left(i_{\mathrm{ex}}=100 \mathrm{~mA} \mathrm{~cm}^{-2}\right)$ at four elemental iodine loadings $([\mathrm{I}]=4,6,8$, and $10 \mathrm{M})$. 


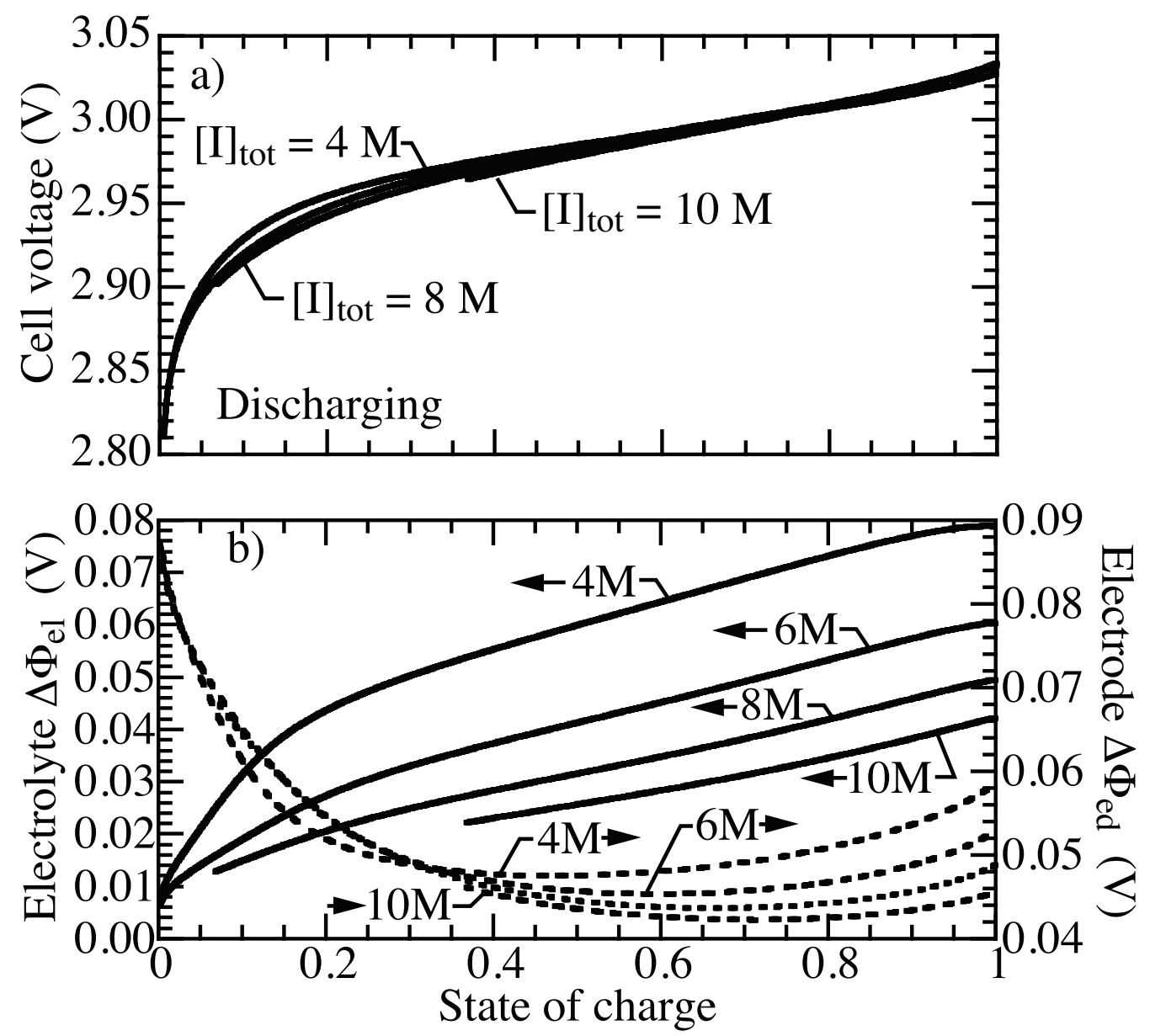

Figure 12: Comparison of the cell voltage and electrostatic potential differences $\left(\Delta \Phi_{\text {ed }}\right.$ and $\Delta \Phi_{\mathrm{el}}$ within the cathode as functions of the state of charge during fixed-rate discharging $\left(i_{\mathrm{ex}}=100 \mathrm{~mA} \mathrm{~cm}^{-2}\right)$ at four elemental iodine loadings $([\mathrm{I}]=4,6,8$, and $10 \mathrm{M})$. 

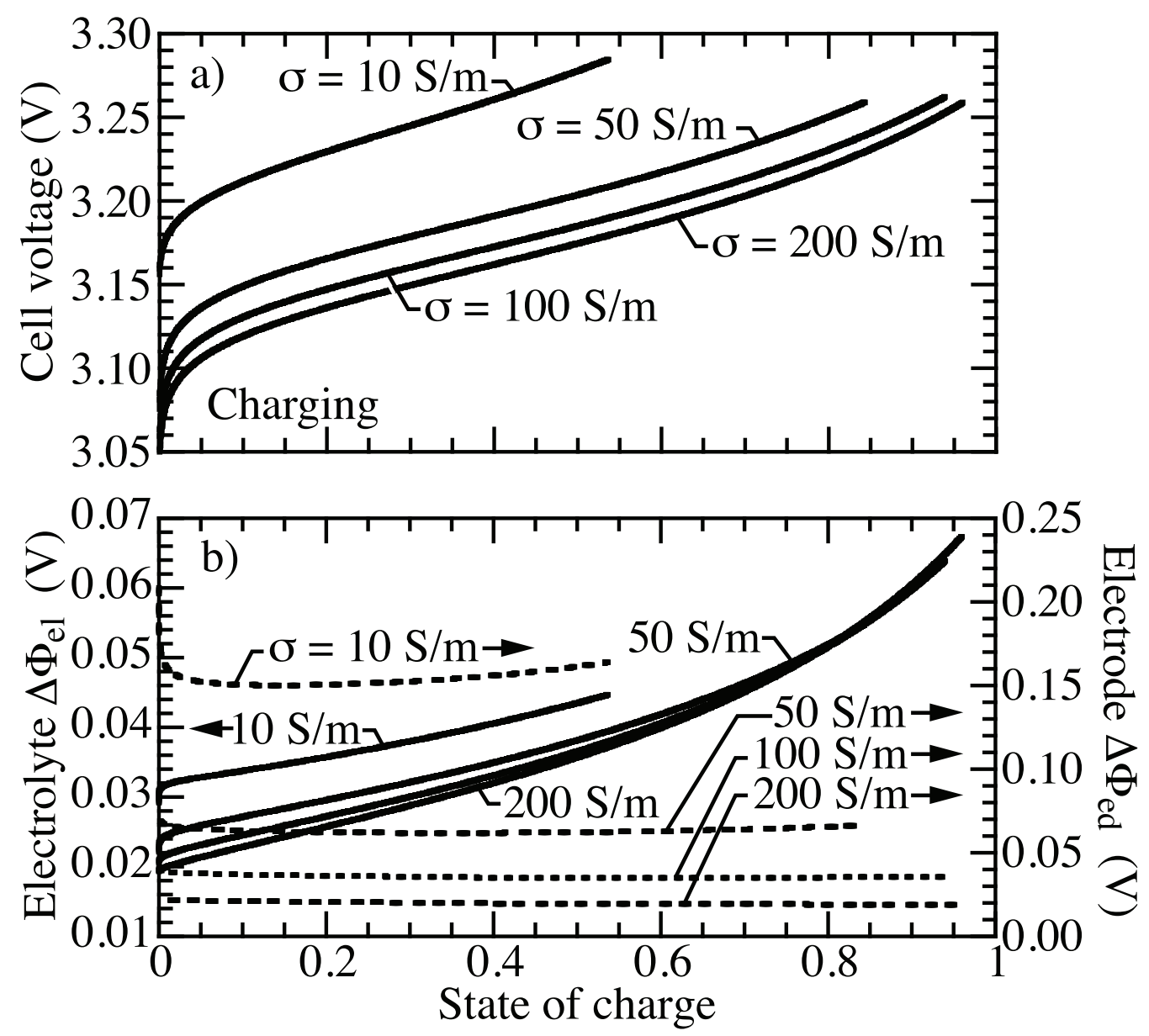

Figure 13: Comparison of the cell voltage and electrostatic potential differences $\left(\Delta \Phi_{\text {ed }}\right.$ and $\Delta \Phi_{\text {el }}$ within the cathode as functions of the state of charge during $1 \mathrm{C}$ fixed-rate charging at four electrode conductivities $\left(\sigma_{\mathrm{ed}}=10,50,100,200 \mathrm{~S} \mathrm{~m}^{-1}\right)$. 


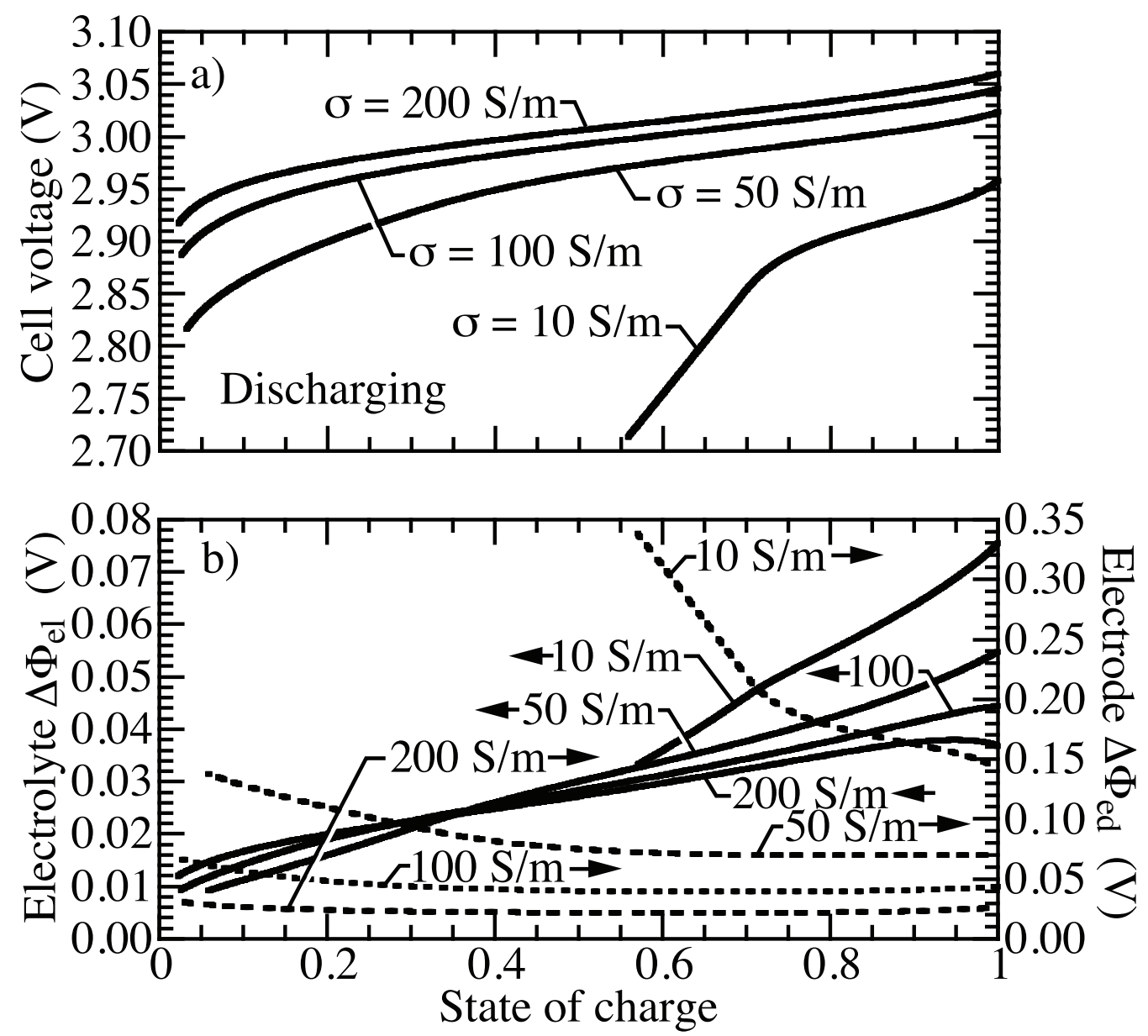

Figure 14: Comparison of the cell voltage and electrostatic potential differences $\left(\Delta \Phi_{\text {ed }}\right.$ and $\Delta \Phi_{\mathrm{el}}$ within the cathode as functions of the state of charge during $1 \mathrm{C}$ fixed-rate discharging at four electrode conductivities $\left(\sigma_{\mathrm{ed}}=10,50,100,200 \mathrm{~S} \mathrm{~m}^{-1}\right)$. 
843

844

845

846

847

848

849

850

851

852

\section{List of Tables}

1 Parameters for diffusion coefficients in a dilute aqueous solution and diffusion coefficients evaluated at $T=25^{\circ} \mathrm{C}$ and $T=120{ }^{\circ} \mathrm{C} \ldots \ldots \ldots \ldots \ldots$

2 Equilibrium molar concentrations under fully discharged and fully charged conditions, with different total elemental iodine concentrations. . . . . . . . . . . . . . . 57

3 Parameters for modeling the $\mathrm{Na}_{2} \mathrm{I}_{2}$ unit cell . . . . . . . . . . . 58

4 Summary comparison of charge and discharge processes at different rates . . . . . . . . . . . . . . . . . . . 59

5 Summary of charge and discharge behaviors at four total iodine loadings. The current density is fixed $i_{\mathrm{ex}}=100 \mathrm{~mA} \mathrm{~cm}^{-2} \quad 60$ 
Table 1: Parameters for diffusion coefficients in a dilute aqueous solution and diffusion coefficients evaluated at $T=25{ }^{\circ} \mathrm{C}$ and $T=120{ }^{\circ} \mathrm{C}$

\begin{tabular}{lccc|cc}
\multicolumn{1}{c}{ Ion } & $A$ & $B$ & $\begin{array}{c}E \\
\left(\mathrm{~kJ} \mathrm{~mol}^{-1}\right)\end{array}$ & $\begin{array}{c}D\left(25^{\circ} \mathrm{C}\right) \\
\left(10^{-5} \mathrm{~cm}^{2} \mathrm{~s}^{-1}\right)\end{array}$ \\
\hline $\mathrm{Na}^{+}$ & $3.1040 \times 10^{-15}$ & +1 & -0.628 & 1.3434 & 6.3867 \\
$\mathrm{I}^{-}$ & $2.4952 \times 10^{-15}$ & +1 & -2.020 & 1.8941 & 7.8625 \\
$\mathrm{I}_{2}$ & $2.3721 \times 10^{-15}$ & +1 & -1.302 & 1.3475 & 5.9989 \\
$\mathrm{I}_{3}^{-}$ & $2.5238 \times 10^{-15}$ & +1 & -0.674 & 1.1130 & 5.2677 \\
\hline
\end{tabular}


Table 2: Equilibrium molar concentrations under fully discharged and fully charged conditions, with different total elemental iodine concentrations.

\begin{tabular}{c|cccc}
\hline Total iodine & \multicolumn{5}{|c}{ Fully discharged } \\
\hline$[\mathrm{I}]$ & {$\left[\mathrm{Na}^{+}\right]_{0}$} & {$\left[\mathrm{I}^{-}\right]_{0}$} & {$\left[\mathrm{I}_{3}^{-}\right]_{0}$} & {$\left[\mathrm{I}_{2}\right]_{0}$} \\
$(\mathrm{M})$ & $(\mathrm{M})$ & $(\mathrm{M})$ & $(\mathrm{M})$ & $(\mathrm{M})$ \\
\hline 4.0 & 4.0 & 4.0 & 0.0 & 0.0 \\
6.0 & 6.0 & 6.0 & 0.0 & 0.0 \\
8.0 & 8.0 & 8.0 & 0.0 & 0.0 \\
10.0 & 10.0 & 10.0 & 0.0 & 0.0 \\
\hline \hline Total iodine & \multicolumn{5}{|c}{ Fully charged } \\
\hline$[\mathrm{I}]$ & {$\left[\mathrm{Na}^{+}\right]_{0}$} & {$\left[\mathrm{I}^{-}\right]_{0}$} & {$\left[\mathrm{I}_{3}^{-}\right]_{0}$} & {$\left[\mathrm{I}_{2}\right]_{0}$} \\
$(\mathrm{M})$ & $(\mathrm{M})$ & $(\mathrm{M})$ & $(\mathrm{M})$ & $(\mathrm{M})$ \\
\hline 4.0 & 1.9048 & 0.8589 & 1.0459 & $1.741 \times 10^{-3}$ \\
6.0 & 2.8571 & 1.2875 & 1.5697 & $1.743 \times 10^{-3}$ \\
8.0 & 3.8095 & 1.7160 & 2.0935 & $1.744 \times 10^{-3}$ \\
10.0 & 4.7619 & 2.1446 & 2.6173 & $1.745 \times 10^{-3}$ \\
\hline
\end{tabular}


Table 3: Parameters for modeling the $\mathrm{Na}-\mathrm{I}_{2}$ unit cell

\begin{tabular}{lrl}
\hline \hline Parameters & Value & Units \\
\hline Anode & & \\
Thickness $\left(L_{a}\right)$ & 1.0 & $\mathrm{~cm}$ \\
Exchange current factor $\left(i_{0}^{\circ}\right)$ & 12.6 & $\mathrm{~A} \mathrm{~cm}^{-2}$ \\
Anodic symmetry factor $\left(\alpha_{\mathrm{a}}\right)$ & 0.5 & \\
Cathodic symmetry factor $\left(\alpha_{\mathrm{c}}\right)$ & 0.5 & \\
\hline Cathode & & \\
Thickness $\left(L_{c}\right)$ & 1.0 & $\mathrm{~cm}$ \\
Porosity $(\phi)$ & 0.8 & \\
Fiber diameter $\left(d_{\mathrm{f}}\right)$ & 10.0 & $\mu \mathrm{m}$ \\
Exchange current factor $\left(i_{0}^{\circ}\right)$ & 1.0 & $\mathrm{~A} \mathrm{~cm}$ \\
Anodic symmetry factor $\left(\alpha_{\mathrm{a}}\right)$ & 0.5 & \\
Cathodic symmetry factor $\left(\alpha_{\mathrm{c}}\right)$ & 0.5 & \\
Rate coefficient $k_{37, \mathrm{f}}$ & $6.0 \times 10^{9}$ & $\mathrm{M}^{-1} \mathrm{~s}^{-1}$ \\
\hline Separator (NASICON) & & \\
Thickness $\left(L_{\mathrm{s}}\right)$ & 0.02 & $\mathrm{~cm}$ \\
\hline
\end{tabular}


Table 4: Summary comparison of charge and discharge processes at different rates

\begin{tabular}{r|rrr|rrr}
\hline \hline & \multicolumn{3}{|c|}{ Charge } & \multicolumn{3}{c}{ Discharge } \\
\hline Rate (C) & Time (s) & SOC & $E_{\text {cell }}$ & Time (s) & SOC & $E_{\text {cell }}$ \\
\hline 0.5 & 6920.5 & 0.9612 & 3.2001 & 7199.0 & 0.0001 & 2.4779 \\
1.0 & 3383.9 & 0.9400 & 3.2623 & 3508.0 & 0.0256 & 2.8867 \\
2.5 & 1085.6 & 0.7539 & 3.5891 & 823.0 & 0.4285 & 2.8445 \\
5.0 & 338.3 & 0.4698 & 3.9556 & 233.0 & 0.6764 & 2.6274 \\
\hline
\end{tabular}


Table 5: Summary of charge and discharge behaviors at four total iodine loadings. The current density is fixed $i_{\mathrm{ex}}=100 \mathrm{~mA} \mathrm{~cm}^{-2}$

\begin{tabular}{c|cc|cc}
\hline Total iodine & \multicolumn{2}{|c|}{ Charge } & \multicolumn{2}{c}{ Discharge } \\
\hline$[\mathrm{I}](\mathrm{M})$ & Time $(\mathrm{s})$ & SOC & Time $(\mathrm{s})$ & SOC \\
\hline 4.0 & 1201.2 & 0.7427 & 1612.0 & 0.0033 \\
6.0 & 2213.2 & 0.9123 & 2420.0 & 0.0024 \\
8.0 & 3027.7 & 0.9360 & 3014.0 & 0.0682 \\
10.0 & 3740.0 & 0.9250 & 2557.0 & 0.3676 \\
\hline
\end{tabular}

